\title{
Autistic traits and individual brain differences: functional network efficiency reflects attentional and social impairments, structural nodal efficiencies index systemising and theory-of-mind skills
}

Subhadip Paul ${ }^{1,2+}$, Aditi Arora ${ }^{2,3+}$, Rashi Midha ${ }^{2,4}$, Dinh Vu ${ }^{5,6}$, Prasun K. Roy ${ }^{2,7}$ and Matthew K. Belmonte ${ }^{2,6,8^{*}}$ (D)

\begin{abstract}
Background: Autism is characterised not only by impaired social cognitive 'empathising' but also by superior rulebased 'systemising'. These cognitive domains intertwine within the categorical diagnosis of autism, yet behavioural genetics suggest largely independent heritability, and separable brain mechanisms. We sought to determine whether quantitative behavioural measures of autistic traits are dimensionally associated with structural and functional brain network integrity, and whether brain bases of autistic traits vary independently across individuals.

Methods: Thirty right-handed neurotypical adults (12 females) were administered psychometric (Social Responsiveness Scale, Autism Spectrum Quotient and Systemising Quotient) and behavioural (Attention Network Test and theory-of-mind reaction time) measures of autistic traits, and structurally (diffusion tensor imaging) and functionally (500 s of $2 \mathrm{~Hz}$ eyes-closed resting fMRI) derived graph-theoretic measures of efficiency of information integration were computed throughout the brain and within subregions.

Results: Social impairment was positively associated with functional efficiency $(r=.47, p=.006)$, globally and within temporo-parietal and prefrontal cortices. Delayed orienting of attention likewise was associated with greater functional efficiency $(r=-.46, p=.0133)$. Systemising was positively associated with global structural efficiency $(r=.38, p=0.018)$, driven specifically by temporal pole; theory-of-mind reaction time was related to structural efficiency $(r=-.40, p=0.0153)$ within right supramarginal gyrus.

Limitations: Interpretation of these relationships is complicated by the many senses of the term 'connectivity', including functional, structural and computational; by the approximation inherent in group functional anatomical parcellations when confronted with individual variation in functional anatomy; and by the validity, sensitivity and specificity of the several survey and experimental behavioural measures applied as correlates of brain structure and function.
\end{abstract}

(Continued on next page)

\footnotetext{
* Correspondence: belmonte@mit.edu

†Subhadip Paul and Aditi Arora are co-first authors.

${ }^{2}$ National Brain Research Centre, NH-8, Nainwal Mode, Manesar 122051, India

${ }^{6}$ Department of Psychology, Chaucer Bldg., Nottingham Trent University,

Shakespeare Street, Nottingham NG1 4FQ, UK

Full list of author information is available at the end of the article
}

C C The Author(s). 2021 Open Access This article is licensed under a Creative Commons Attribution 4.0 International License, which permits use, sharing, adaptation, distribution and reproduction in any medium or format, as long as you give appropriate credit to the original author(s) and the source, provide a link to the Creative Commons licence, and indicate if changes were made. The images or other third party material in this article are included in the article's Creative Commons licence, unless indicated otherwise in a credit line to the material. If material is not included in the article's Creative Commons licence and your intended use is not permitted by statutory regulation or exceeds the permitted use, you will need to obtain permission directly from the copyright holder. To view a copy of this licence, visit http://creativecommons.org/licenses/by/4.0/ The Creative Commons Public Domain Dedication waiver (http://creativecommons.org/publicdomain/zero/1.0/) applies to the data made available in this article, unless otherwise stated in a credit line to the data. 


\begin{abstract}
(Continued from previous page)
Conclusions: Functional connectivities highlight distributed networks associated with domain-general properties such as attentional orienting and social cognition broadly, associating more impaired behaviour with more efficient brain networks that may reflect heightened feedforward information flow subserving autistic strengths and deficits alike. Structural connectivity results highlight specific anatomical nodes of convergence, reflecting cognitive and neuroanatomical independence of systemising and theory-of-mind. In addition, this work shows that individual differences in theory-of-mind related to brain structure can be measured behaviourally, and offers neuroanatomical evidence to pin down the slippery construct of 'systemising' as the capacity to construct invariant contextual associations.
\end{abstract}

Keywords: Autism, Dimensional, Social, Attention, Theory-of-mind, fMRI, DTI, Functional connectivity, Graph theory

\section{Background}

The twenty-first century science and public rhetoric of autism have been dominated by a shift from exclusively categorical construal as a disease condition to a recognition of dimensional autistic traits throughout the general population. In this regard, autism and autistic traits have mirrored axes of variation within other complex neuropsychiatric conditions such as schizophrenia and schizotypy [1], or obsessivecompulsive disorder and obsessionality, compulsivity and ordering [2]. Although specific patterns of variation may converge on general graph-theoretic hub territories such as prefrontal cortex in schizophrenia, the devil is in the details, and studies do not in general agree [3, 4] on how exactly these dimensional trait measures map onto dimensional variations in brain connectivity. Categorical autism is distinguished by brain dysconnectivity $[5,6]$, and as the construal of autism has extended to dimensional traits, so have such dimensional behavioural and cognitive traits begun to be related to dimensional variation in brain connectivity [7]. These dimensional relationships complement and interact with categorical differences [8], no doubt presenting developmental endpoints of complex interactive specialisation $[9,10]$. But are broadly defined and broadly surveyed social and perceptual 'autistic' traits fundamentally neurally related to autism itself, or are they but reflections of individual variation? [11].

Neurophysiological variables have been shown to covary with behavioural measures of such traits, but these behavioural measures have been dominated by ones that focus on social communication in particular, most commonly the well validated and oft used Social Responsiveness Scale [12], and by informant-report or even selfreport surveys rather than experimental measures. Although the canonical social communicative result on autism is apparent impairment in theory-of-mind, the past three and a half decades have not yielded convergence on any single scale by which this deficit ought to be measured. In general, different tests of theory-ofmind seem to agree less with each other and more in terms of their various confounds [13], such as working memory and language. The main approach to resolving the binary outcome of the original, 'Sally-Anne' test of theory-of-mind into a continuous measure has been to sum binary item scores across multiple test scenarios, with checks for comprehension [14, 15]; a complementary approach is to average reaction times across repeated trials of ToM versus non-ToM scenarios [16]. As the former, accuracy-based method tends to yield ceiling effects in non-autistic populations; in this study of dimensional autistic traits, we implement the latter, reaction-time approach, within a motivating, gamebased context [17] whose graphical presentation minimises verbal confounds.

Social communication can be the most obvious of autistic traits but is far from the only axis of variation, and experimental measures can yield information more direct and domain-specific, complementary to that provided by surveys. Dimensional brain-behaviour relationships may vary across behavioural domains and across types of behavioural assay, and questions remain as to whether and how such relationships differ across sensory/perceptual, attentional, social cognitive, and verbal tasks, and across survey and experimental behavioural measures. Might behaviourally measured correlations between social and non-social autistic traits $[18,19]$ persist into the realm of brain function? Or do these dimensional traits have independent brain bases reflecting their mostly independent heritability [7, 20-22]? And do survey and experimental behavioural measures yield similar results?

At the same time as behavioural measures can be extended, so can metrics of brain structure and function. The field has witnessed a shift from raw measures of diffusion anisotropy and temporal correlation to derived graph-theoretic metrics that address more specifically the networks subserving neural information transfer [23]. Pathways between brain regions can be represented as a graph-theoretic complex networked system, where regions are vertices and pathways are edges of the network [24]. Such mathematical representation of whitematter pathways is known as a 'structural connectome' [24, 25], defined by anatomical connections. The functional connectome, on the other hand, represents relations between brain regions' functional activities [26], where graph edges are defined as cross-correlations between time series of functional activations. Graph- 
theoretic complex network measures allow characterisation of structural and functional brain networks at global and nodal/regional levels [27].

Whole-brain associations between the graph-theoretic resting-state functional network measures, DTI-derived measures of localised white-matter integrity, and psychometrics including the Social Responsiveness Scale and Autistic Spectrum Screening Questionnaire have been explored previously [28], linking autistic traits with reduced average local (but not global) functional efficiency (a graph-theoretic measure of how well neural networks integrate information from disparate sources) overall, and in right posterior cingulum in particular. Associations between the Social Responsiveness Scale scores and rs-fMRI connectivity were also explored in a regionof-interest approach centred on rostral anterior cingulum [29], finding reduced correlation with mid-insula and heightened correlation with lateral occipital cortex, superior parietal cortex and angular gyrus. However, structural connectome measures as a function of dimensional autistic traits have only recently begun to be assayed [30].

This preliminary study applies both survey and experimental measures to identify dimensional variation in brain-behaviour relationships, across both social and non-social behavioural and cognitive domains of autistic traits in the normal population, using graph-theoretic metrics derived from both functional (resting fMRI) and structural (DTI) measures of brain connectivity. We ask which combinations of behavioural (survey and experimental, social and non-social) and brain (structural and functional) measures might be sensitive to such brainbehaviour dimensions. The straightforward hypotheses are an association of broad measures of autistic traits with reduced local functional network integrity (low efficiency, low clustering, long path length) across the entire brain [28], alongside similar effects within anatomical regions functionally associated with specific constructs and their measures (e.g. impaired theory-of-mind with right temporoparietal junction [31], slowed orienting of attention with intraparietal sulcus [32], impaired executive control with anterior cingulum [28, 33], superior systemisimg with posterior parietal cortex and impaired empathising with frontotemporal cortices [34]).

\section{Methods}

\section{Subjects}

Thirty right-handed volunteers (mean age \pm standard deviation: 27.29 years \pm 2.88 , 18 males, 12 females) participated in the study for small monetary reimbursement. All participants had normal or corrected-tonormal vision, and no history of psychological or neurological disorders. Written informed consent was obtained from participants.

\section{Behavioural measures}

Five questionnaires and three computer-based psychometric tests along with two tests of verbal fluency were administered (Table 1, Additional file 1). All participants completed the adult version of the Autism Spectrum Quotient (AQ [35]). On the basis of our previous work [18] in which granular scoring of the AQ made a more sensitive correlate of other measures of autistic traits, the AQ was scored on a symmetric 4-point Likert scale. AQ subcategory scores were recorded, both the social subscore AQSoc comprising attention switching (AQAttSw), communication (AQComm), imagination (AQImag) and social skills (AQSS), and the details/patterns subscore (AQDet). Participants' self-reported ability to understand others' intentions, predict their behaviour, and respond with appropriate emotions were measured with the Empathy Quotient (EQ) [36].

The Systemizing Quotient (SQ) [37] assessed the drive to build contexts from individual parts and details. 'Systemizing', having been a somewhat nebulously defined construct, deserves some explication. Baron-Cohen et al. define a 'system', in this context, as "something that takes inputs, which can then be operated on in variable ways, to deliver different outputs in a rule-governed way" [37]. More specifically, a system might map between concrete motor outputs and sensory inputs, as with a fidget spinner, or between mechanical causes and effects, as with an engine, or between logical parameters input and results output, as with a computer, or between books or records and their linearly or hierarchically ordered classification numbers, as in a library. The face validity in relation to autistic preferences and expertise at classifying, ordering and predicting within explicitly defined systems seems clear enough. However, the SQ's construct validity as a measure of drive to understand rule-based input-output relations has been called into question by its lack of any strong relationship to mathematical skill [38]. The SQ's questions focus on construction, spatial mappings, component parts, component mechanisms and processes, and taxonomies (described by Ling et al. [39] as 'DIY', 'topography', 'structure', 'technicity' and 'taxonomy', respectively) -all processes that emphasise spatially and temporally invariant, static and therefore predictable relations of parts and details to frames and contexts, and thus reflect an autistic cognitive style of bricolage, in which abstract and general representations are effortfully, extensionally constructed bottom-up from the underlying details and instances [40]. Baron-Cohen's systemizing construct thus is not so much a drive to understand rule-based input-output relations as it is a skill of constructing invariant contextual associations. SQ scores map onto population-level sex differences in cognitive traits related to autism [41], males being on average more prone to the SQ's systemizing approach to cognition, and females being greater at the cognitive empathy tapped by same group's 'Empathizing Quotient'. 
Table 1 Mean and standard deviation of all behavioural measures

\begin{tabular}{|c|c|c|c|}
\hline Behavioural measures & Female & Male & Total \\
\hline \multicolumn{4}{|l|}{$\mathrm{AQ}$} \\
\hline Mean & -18.92 & -19.56 & -19.24 \\
\hline$S D$ & 27.16 & 19.18 & 23.17 \\
\hline \multicolumn{4}{|l|}{ EQ } \\
\hline Mean & 45.75 & 39.39 & 42.57 \\
\hline$S D$ & 12.73 & 11.20 & 11.97 \\
\hline \multicolumn{4}{|l|}{ SQ } \\
\hline Mean & 64.92 & 74.56 & 69.74 \\
\hline SD & 15.89 & 17.25 & 16.57 \\
\hline \multicolumn{4}{|l|}{ SSQ } \\
\hline Mean & 5.75 & 3.50 & 4.63 \\
\hline SD & 2.45 & 1.50 & 1.98 \\
\hline \multicolumn{4}{|l|}{ SRS } \\
\hline Mean & 33.00 & 42.76 & 37.88 \\
\hline SD & 12.88 & 25.67 & 19.27 \\
\hline \multicolumn{4}{|l|}{ RMET } \\
\hline Mean & 27.64 & 25.44 & 26.54 \\
\hline$S D$ & 4.95 & 4.68 & 4.81 \\
\hline \multicolumn{4}{|l|}{ COWA } \\
\hline Mean & 49.00 & 43.11 & 46.06 \\
\hline SD & 14.21 & 7.94 & 11.08 \\
\hline \multicolumn{4}{|l|}{ AnNT } \\
\hline Mean & 18.00 & 16.50 & 17.25 \\
\hline$S D$ & 5.59 & 4.59 & 5.09 \\
\hline \multicolumn{4}{|l|}{ FC-EFT } \\
\hline Mean & 11410.41 (ms) & 8815.5 (ms) & 10112.95 (ms) \\
\hline$S D$ & 5561.96 (ms) & 5002.31 (ms) & 5282.13 (ms) \\
\hline \multicolumn{4}{|l|}{ ANT (alerting effect) } \\
\hline Mean & 48.25 (ms) & 51.70 (ms) & 49.97 (ms) \\
\hline SD & 34.53 (ms) & 28.56 (ms) & 31.54 (ms) \\
\hline \multicolumn{4}{|l|}{ ANT (orienting effect) } \\
\hline Mean & 58.166 (ms) & 48.05 (ms) & 53.11 (ms) \\
\hline SD & 37.64 (ms) & 20.97 (ms) & 29.31 (ms) \\
\hline \multicolumn{4}{|l|}{ ANT (conflict effect) } \\
\hline Mean & 116.33 (ms) & 114.64 (ms) & 115.49 (ms) \\
\hline SD & 38.56 (ms) & 40.14 (ms) & 39.35 (ms) \\
\hline \multicolumn{4}{|l|}{ ANT (grand mean effect) } \\
\hline Mean & 656.33 (ms) & 620.52 (ms) & 638.43 (ms) \\
\hline$S D$ & 60.32 (ms) & 34.16 (ms) & 47.24 (ms) \\
\hline \multicolumn{4}{|l|}{ Second-order ToM } \\
\hline Mean & $-5.20(\mathrm{~s})$ & $-0.063(\mathrm{~s})$ & $-2.63(\mathrm{~s})$ \\
\hline SD & $4.95(s)$ & $10.61(s)$ & $7.78(s)$ \\
\hline
\end{tabular}

Table 1 Mean and standard deviation of all behavioural measures (Continued)

\begin{tabular}{|c|c|c|c|}
\hline Behavioural measures & Female & Male & Total \\
\hline \multicolumn{4}{|l|}{ Egocentric first-order ToM } \\
\hline Mean & $6.984(s)$ & $1.183(\mathrm{~s})$ & 4.08 (s) \\
\hline$S D$ & $14.01(s)$ & $18.65(s)$ & $16.33(s)$ \\
\hline \multicolumn{4}{|l|}{ Allocentric first-order ToM } \\
\hline Mean & $3.94(\mathrm{~s})$ & $0.548(s)$ & $2.24(\mathrm{~s})$ \\
\hline$S D$ & $5.160(s)$ & $11.477(s)$ & $8.31(s)$ \\
\hline \multicolumn{4}{|l|}{ WASI (verbal IQ) } \\
\hline Mean & 109.42 & 109.67 & 109.54 \\
\hline$S D$ & 9.89 & 7.90 & 8.90 \\
\hline \multicolumn{4}{|l|}{ WASI (performance IQ) } \\
\hline Mean & 102.00 & 109.17 & 105.58 \\
\hline SD & 6.66 & 7.08 & 6.87 \\
\hline \multicolumn{4}{|l|}{ WASI (full-scale IQ) } \\
\hline Mean & 106.83 & 110.89 & 108.86 \\
\hline SD & 7.52 & 7.54 & 7.53 \\
\hline
\end{tabular}

AQ Autism Spectrum Quotient, EQ empathy quotient, SQ systemizing quotient, SSQ Sensory Sensitivity Questionnaire, SRS Social Responsiveness Scale, RMET Reading the Mind in the Eyes Test, COWA Controlled Oral Word Association test, AnNT Animal Names Test, FC-EFT forced-choice version of the Embedded Figures Test, ANT Attention Network Task, WASI Wechsler Abbreviated Scale of Intelligence

Autistic sensory traits were assessed by the Sensory Sensitivity Questionnaire (SSQ) [42-45]. At the time of data collection, few self-report or informant-report measures of sensory processing quick enough to be acceptable to subjects in this multi-measure study were yet available (see Table 3 of DuBois et al. [46]), and those that were available had been used in categorical contrasts of autistic and non-autistic populations (e.g. [47]) rather than as dimensional measures-a trend that continues today. Thus, the selection of a sensory measure was based on a combination of free availability and face validity for autism, its use as a dimensional measure being necessarily an extrapolation.

To assess autistic social communicative traits, the Social Responsiveness Scale- Adult (SRS) [12] was completed by subjects' social partners (e.g. spouse, parent, longtime friend). The SRS was developed as a measure of subthreshold autistic traits and has accumulated an extensive history and norms for use as such. One subject did not return the SRS.

Social cognition also was measured by the 'Reading the Mind in the Eyes' Test (RMET) [48]. The RMET originally was developed as a test of the ability to infer another's mental state, its face validity being established by its covariance with other quantitative measures of autism spectrum conditions and autistic traits. It has been applied widely as a dimensional measure of autistic traits (e.g. $[18,49])$. Later work demonstrates that the RMET 
measures more the ability to name emotions [50], and verbal ability in general [51], although with this interpretive caveat the RMET remains useful as a measure of social cognitive function in the broad sense. The test comprises 36 photographs of the eye region, for each of which participants choose the one of four words that best describes what the person in the picture is feeling or thinking.

Perceptual disembedding was measured by a forcedchoice version of the Embedded Figures Test (FC-EFT) $[52,53]$. Subjects were asked to locate the embedded shape as rapidly as possible with a 50 -s timeout interval, pressing the number key 1 for the shape on the left or the number key 9 for the shape on the right. The score is the mean latency of correct responses. The EFT has been applied in many studies of dimensional autistic traits (e.g. [18]), though a review of these by Cribb et al. [54] suggests that the EFT may be most effective when applied categorically or between extremes rather than along a continuum of dimensional variation.

The Attention Network Test Revised (ANT-R) [33, 55] combines the Posner visual attention task [56] with a visual spatial flanker task [57] to measure alerting (temporal effect of cueing), orienting (spatial effect of cueing), and executive control over conflicts between percept-action mappings (effect of flanker congruence), the final two of which, at least, are demonstrably perturbed in autism [58]. Scores were computed as simple differences of mean reaction times in trials with correct responses: alerting, central cue minus no cue; orienting, spatial cue minus central cue; conflict, no cue with incongruent flankers minus no cue with congruent flankers. The ANT has been validated against self-report measures of individual differences in attentional control [59], though not to our knowledge in terms of autistic traits per se.

Phonetic association fluency was measured by the Controlled Oral Word Association (COWA) test [60]. The COWA evaluates the spontaneous, timed production of words beginning with a given letter. In three 1min trials, participants were asked to generate as many words as possible beginning with ' $\mathrm{F}$ ', 'A' and 'S', respectively, excluding proper names and names of numbers. The score was the mean tally of qualifying words, excluding repetitions, across the three trials. Subjects also completed the Animal Names Test [61], a semantic fluency test in which subjects are asked to generate in a 1min timed trial as many animal names as possible, excluding the names of fish, birds and snakes. The score is the total number of qualifying animal names, excluding repetitions. Similar phonetic and semantic fluency tasks have been oft applied in measurement of individual differences [62].
Egocentric and allocentric [63] first-order theory-ofmind (ToM), and second-order ToM, were assessed as reaction time differences between conditions in a graphical version of the Sally-Anne test. This task was implemented as a computer game [17] (see Supplementary Methods) wherein Sally is a friendly spaceship captain, Anne is a space pirate, the ball is a cache of resources for the player's space station, and the basket and the box each are one of four planets distinguished by spatial position, colours and texture. The resulting no-theft, unobserved-theft and observed-theft vignettes were presented mainly graphically, supplemented by simple textual narrative at the bottom of the display. The subject was reminded that Sally would always steer her spaceship where she thought the cache was, and was asked to set a course to meet up with her by moving a trackpad cursor up, down, left or right to one of the four planets.

To assess general intelligence, participants were tested with the Wechsler Abbreviated Scale of Intelligence (WASI) [64]. The WASI's four subtests estimate verbal comprehension and perceptual reasoning abilities that contribute to general intelligence.

\section{Image acquisitions}

MR image acquisitions were performed using a 3 Tesla Philips Achieva scanner with eight-channel head coil. The head was immobilised using cushions and straps. During the resting-state fMRI data acquisition, participants were asked to keep their eyes closed, relax and not think about anything specific, but to avoid sleeping. All participants confirmed that they did not sleep and did not come close to falling asleep during the scan. Resting-state Blood Oxygen Level Dependent (BOLD) signals were acquired using a 3D PRESTO (principles of echo shifting with a train of observations) sequence $[65$, 66] with the following parameters: field of view (FOV) $256 \mathrm{~mm} \times 256 \mathrm{~mm} \times 140 \mathrm{~mm}$, voxel dimension $4 \mathrm{~mm} \times$ $4 \mathrm{~mm} \times 4 \mathrm{~mm}, 1000$ time points, dynamic scan time 500 $\mathrm{ms}$, repetition time (TR) $22 \mathrm{~ms}$, echo time (TE) (shifted) $32 \mathrm{~ms}$, SENSE $\mathrm{p}$ reduction $=2$, SENSE $\mathrm{s}$ reduction $=2$, flip angle (FA) $9^{\circ}$. This high-frequency $(2 \mathrm{~Hz})$ sampling minimises aliasing of high-frequency $(\sim 0.1-1 \mathrm{~Hz})$ cardiac and respiratory oscillations into the slower (0.01-0.1 Hz) spontaneous fluctuations of BOLD signal. However, these fMRI parameters yield lower anatomical contrast compared to T1-weighted images. This $9^{\circ}$ functional scan therefore was followed by a similar PRESTO scan at $25^{\circ}$ flip angle for use in spatially co-registering the PRESTO images against T1-weighted anatomical images [67]. Lastly, a 3D T1-weighted image (Additional files 2, 3, 4, 5 and 6) was acquired using a Turbo Field Echo sequence with the following parameters: FOV 240 $\mathrm{mm} \times 240 \mathrm{~mm} \times 160 \mathrm{~mm}$, voxel dimension $=1.0 \mathrm{~mm}^{3}$ isotropic, TR $8 \mathrm{~ms}$, TE $3.69 \mathrm{~ms}$, flip angle $8^{\circ}$. 
Diffusion-weighted images were obtained using a spinecho (SE) echo-planar imaging (EPI) sequence, FOV 224 $\mathrm{mm} \times 224 \mathrm{~mm} \times 140 \mathrm{~mm}$, voxel dimension $=2 \mathrm{~mm} \times 2$ $\mathrm{mm} \times 2 \mathrm{~mm}, \mathrm{TR} / \mathrm{TE}=9386 / 58 \mathrm{~ms}$, diffusion gradient timing $\left(\Delta / \delta=28.9 / 17.8 \mathrm{~ms}, b=1000 \mathrm{~s} / \mathrm{mm}^{2}, 32\right.$ directions, with fat suppression using Spectral Presaturation by Inversion Recovery (SPIR). The sequence was repeated three times (total gradient directions $=96$ ) in order to improve the quality of the diffusion-weighted signals. Fifteen volumes with no diffusion weighting $(b=$ $0 \mathrm{~s} / \mathrm{mm}^{2}$ ) were also acquired.

\section{Preprocessing}

Individual fMRI scans were spatially re-aligned to the last functional volume using Statistical Parametric Mapping (SPM) software. Then, the high-contrast $25^{\circ}$ PRESTO scan was spatially co-registered to these realigned fMRI scans and each T1-weighted image was linearly transformed onto it using the default setting of FLIRT (FMRIB's Linear Image Registration Tool). T1-weighted images were segmented into grey matter (GM), white matter (WM) and cerebrospinal fluid (CSF) maps using FAST (FMRIB's Automated Segmentation Tool), and these maps were transformed to the realigned PRESTO scans using applyxfm function of FSL (FMRIB Software Library). Nearest-neighbour interpolation was used so as to avoid introducing partial-volume tissue categories whilst spatially transforming the segmented maps. Further processing took place in DPARSF (Data Processing Assistant for Resting-State fMRI) [68]. The first 10 volumes of the realigned fMRI scans were discarded and the remaining fMRI time series with 990 time points were detrended. Averaged WM and CSF signals were from the fMRI time series using the realigned tissue-segmented maps as masks. This and head motion parameters were regressed out (Additional file 7) from the fMRI time series. High-frequency respiratory and cardiac oscillations (0.1-1 $\mathrm{Hz})$ and low-frequency scanner drift $(<0.01 \mathrm{~Hz})$ were removed by band-pass filtering at $0.01-0.1 \mathrm{~Hz}$ [69]. The fMRI datasets were not spatially smoothed, as smoothing is inherent in spatially averaging the time series from each region of interest (described in the subsection on "Network construction").

We have concatenated the three sets of diffusion imaging data and the gradient tables. In order to correct the distortion of diffusion-weighted images due to eddy currents and head motion, the diffusion-weighted images of each participant were registered to the respective first $b=0$ image using affine transformation. Rotational components corresponding to each diffusion-weighted volume were extracted from the transformation matrix, and the B-matrix was rotated using the extracted rotation vector in order to correct for head motion [70].

\section{Modelling of diffusion-weighted signals}

Diffusion-weighted signal in each voxel was modelled considering multiple fibre orientations in the voxel. Metropolis-Hastings Markov Chain Monte Carlo sampling was used for estimation of model parameters and a Bayesian method, Automatic Relevance Determination (ARD), was applied to determine whether the diffusionweighted signals of a voxel should be represented by a single-fibre or a multiple-fibre model [71]. Diffusionweighted data were modelled using the bedpostx function of FDT (FMRIB's Diffusion Toolbox) with default values of the parameters.

\section{Network construction}

A network with $N$ nodes and $K$ edges can be denoted by a graph $(G(N, K))$ [72]. The rows and columns of the $N \times$ $N$ adjacency matrix represent the nodes and each element $\left(w_{i j}\right)$ of this matrix denotes the link between the $i$ th and the $j$ th nodes of the network. We describe the procedures to construct adjacency matrices to represent the functional and structural connectivity networks below.

\section{Correlation matrix}

Using FNIRT (FMRIB's non-linear image registration tool), the ICBM152 T1 template was non-linearly registered to each participant's preprocessed fMRI scans, by using the PRESTO-aligned T1-weighted image as the registration target. This spatial transformation was then applied to the AAL-90 atlas label map using FSL's applywarp function, with nearest-neighbour interpolation to retain the values of the atlas labels. The resulting AAL90 map registered to each individual participant's functional scans was masked using that participant's similarly registered tissue segmentation map to select only grey matter voxels.

Using this grey matter AAL-90 label map, the averaged time series corresponding to each AAL-90 brain area was extracted from the preprocessed fMRI scans. The symmetric $90 \times 90$ correlation matrix (Additional file 8) for each participant was constructed by calculating the zero-lagged Pearson correlation coefficient between all pairs of BOLD time series. Each element $\left(w_{i j}\right)$ of the correlation matrix is the correlation between the time series extracted from the $i$ th and the $j$ th AAL-90 regions. Zeroes have been assigned to the diagonal.

\section{Connection matrix}

Similarly to the preprocessing of the functional images described above, T1-weighted images were rigidly registered to the corresponding first $b=0$ image using FLIRT, segmented GM maps were linearly transformed to the corresponding $b=0$ space, the $b=0$-registered T1-weighted images were non-linearly registered to the ICBM152 T1 template using FNIRT and AAL-90 label maps were 
warped to the $b=0$ images using the inverted non-linear transformations with nearest-neighbour interpolation. The voxels of the label map that corresponded to grey matter in the $b=0$-registered segmented GM map were selected for tractography.

Probabilistic tractography was executed from each brain area to the other 89 brain areas using FDT (FMRIB's Diffusion Toolbox). For every sampled streamline fibre at the seed voxel, a sample direction was selected from the local direction distribution. Moving 0.5 $\mathrm{mm}$ to a new location along the sample direction, a new sample direction was selected from the direction distribution at that new location. Five thousand streamline fibres were sampled from each seed voxel in the probabilistic tractography framework. Let us consider a brain area comprising $n$ voxels. Dividing the number of fibres passing through that area by $n \times 5000$ yields the connection probability from the seed area to the given area. However, the connection probability of the $i$ th brain area to the $j$ th brain area is not necessarily equal to the connection probability of the $j$ th brain area to the $i$ th brain area. We have calculated undirected connection probability between those two areas $\left(P_{i j}\right)$ by taking the average of those two probabilities. A symmetric connection matrix (Additional file 8) of dimension $90 \times 90$ for each participant was constructed by performing probabilistic tractography from all 90 brain areas. Each element $\left(w_{i j}\right)$ of the connection matrix denotes the undirected connection probability between the $i$ th and the $j$ th AAL-90 regions. Zeroes have been assigned to the diagonal.

\section{Network metrics}

Using the brain connectivity toolbox [27], we have calculated the functional and the structural network metrics for each participant from the corresponding correlation matrix and the connection matrix respectively, the coefficient in each matrix cell serving as an adjacency weight for the corresponding pair of AAL-90 regions. As we are interested not in whole-group patterns but in individual differences, weights have not been thresholded [6]; any non-zero weight represents some measure of adjacency. This strategy avoids the potential of artefactually generating disconnected graph components which could skew the measures in some subjects. In selecting these metrics, we have taken a cue from previous studies of autism and autistic traits: Billeci et al. [30] used characteristic path length and clustering coefficient, and Jakab et al. [28] used local and global efficiency. A deficit in "smallworld" network topology, defined as a combination of high density of connections for computation within local neural neighbourhoods and direct connection routes for information transfer between these neighbourhoods, has been cited as a distinguishing characteristic of the autistic brain [73]. Small-world topology is maintained by minimising 'wiring' connections whilst maintaining strong clustering; small characteristic path length and large clustering coefficient, therefore, constitute perhaps the most straightforward graph-theoretic metrics of complexity. Global and local efficiencies are related to path length and clustering, respectively, but efficiency can be a more powerful derived metric for empirical data, because its summation of reciprocals of path lengths gives weight to hubs and parallel connections rather than to disconnected regions and serial connections [74].

\section{Strength}

Strength of the $i$ th node $\left(s_{i}^{w}\right)$ of the network is denoted by the summation over the edge weights $\left(w_{i j}\right)$ of all links to the $i$ th node:

$$
s_{i}^{w}=\sum_{j \in N} w_{i j}
$$

The value of the nodal strength reveals the significance of that node in the network [27].

\section{Characteristic path length}

The characteristic path length of a network is defined as the average shortest path length between all pairs of nodes in the network [27]:

$$
L^{w}=\frac{1}{N} \sum_{\mathrm{i} \in N} \frac{\sum_{i \in N, j \neq i} d_{i j}^{w}}{N-1}
$$

where $d_{i j}^{w}$ (the inverse of connection strength, $w_{i j}$ ) denotes the element of weighted distance matrix $\left(d^{w}\right)$. Characteristic path length is a global measure of integration in a network.

\section{Clustering coefficient}

The weighted clustering coefficient of the $i$ th node of the network $\left(C_{i}^{w}\right)$ is defined [75] as

$$
C_{i}^{w}=\frac{\sum_{j, m \in N}\left(w_{i j} w_{i m} w_{j m}\right)^{\frac{1}{3}}}{k_{i}\left(k_{i}-1\right)}
$$

where $k_{i}$ stands for the weighted degree, $k_{i}=\sum_{j \in N} w_{i j}$. When $k_{i}=0$ or 1 , a zero value is assigned to the clustering coefficient of that node. The clustering coefficient is a network-based measure of segregation which denotes the ability of specialised processing within densely connected brain regions $[27,76]$. The nodal clustering coefficient represents how strongly a node is clustered with its neighbouring nodes. The global clustering coefficient of a network is calculated by taking the average of the clustering coefficients over all the nodes of the network: 


$$
C^{w}=\frac{1}{N} \sum_{i \in N} C_{i}^{w}
$$

The clustering coefficient of a network $\left(C^{w}\right)$ characterises the level of interconnectivity of the network.

\section{Global and local efficiencies}

Global and local efficiencies measure the integration of information from distributed brain areas and estimate how well these brain areas communicate. Global efficiency of the network is computed using the following expression [77]:

$$
E_{\mathrm{glob}}^{w}=\frac{1}{N} \sum_{i \in N} \frac{\sum_{j \in N, j \neq i}\left(d_{i j}^{w}\right)^{-1}}{N-1}
$$

On the other hand, local efficiency of the $i$ th node of the network is the global efficiency of the neighbourhood of that node [27]:

$$
E_{\mathrm{loc}, i}^{w}=\frac{1}{2} \sum_{i \in N} \frac{\sum_{j, m \in N, j \neq i}\left(w_{i j} w_{j m}\left[d_{j m}^{w}\left(N_{i}\right)\right]^{-1}\right)^{\frac{1}{3}}}{k_{i}\left(k_{i}-1\right)}
$$

where $d_{j m}^{w}\left(N_{i}\right)$ denotes the shortest path between the $j$ th and $m$ th nodes which are within the neighbourhood of the $i$ th node.

\section{Statistical analyses}

Behavioural measures and the functional and structural network metrics were z-transformed. Behavioural measures were correlated with the network metrics using multi-linear regression. Age, gender, full-scale IQ, head-motion effect (average frame-wise displacement [78]) and brain volumes were considered as confounding factors, and were removed from the neuroimaging-based measures using multiple linear regression. Spearman correlation coefficients between the resulting residuals of the neuroimaging-based measures and the behavioural measures were computed across all subjects. Tail probabilities, one-sided with respect to whichever tail was nearest, were estimated using permutation testing (as in the supplementary information of [79]) as $\left[\min \left(\mid\right.\right.$ p $_{\text {rand }} \mid$ $\left.\left.\left.\rho_{\text {obs }}>\rho_{\text {rand }}\right\}||,\left\{\rho_{\text {rand }} \mid \rho_{\text {obs }}<\rho_{\text {rand }}\right\} \mid\right)+1\right] / N$ where $\rho_{\text {obs }}$ is the Spearman correlation computed from the actual data and the $\rho_{\text {rand }}$ are the $N=10000$ Spearman correlations computed on the $N=10000$ random permutations of the data (Additional file 9). Statistical significances of the correlations between the nodal/regional neuroimaging-based measures and each behavioural measure were thresholded at $5 \%$ false discovery rate (FDR) [80], except in the case of theory-of-mind measures with an a priori hypothetical association with brain regions in the right temporoparietal junction. Effect sizes are indicated by absolute values of the correlation coefficients.

\section{Results}

Global functional clustering, characteristic path length and efficiency correlated with Social Responsiveness Scale (Table 2). This global association was driven by nodal strength, clustering and efficiency in a network spanning most of the cerebral cortex (as well as putamen and globus pallidus), with strength differences in prefrontal, medial-anterior temporal and temporoparietal cortices (full details in Table 3). Global functional clustering, characteristic path length and efficiency also correlated with the orienting score on the Attention Network Test (Table 2). This global association was driven by nodal clustering (but not significantly by nodal strength or efficiency) in a similarly widespread cerebral network encompassing a smaller number of regions in prefrontal, temporal and parietal cortices as well as putamen and globus pallidus (full details in Table 4, illustrated in Fig. 1). We have not observed any significant associations between global $(p>0.05)$ or nodal (pFDR > 0.05 ) functional network measures and other behavioural measures (Table 2).

Global structural clustering and efficiency correlated with Systemizing Quotient (SQ) scores $(p<0.05)$ (Table 5). This global association was driven by nodal strength, clustering and efficiency in a network comprising the medial temporal lobes and right temporal pole (full details in Table 6, illustrated in Fig. 1). At the nodal level, allocentric first-order theory-of-mind reaction time difference was associated with efficiency ( $\rho=-0.397$, one-tailed $p=0.0153$ ) and clustering ( $\rho=-0.400$, one-tailed $p=0.014$, both uncorrected given a priori association of theory-of-mind with right temporoparietal junction) in right supramarginal gyrus, which was the only brain region to manifest any significant uncorrected correlation with theory-of-mind. We have not observed any significant associations between global $(p>0.1)$ or nodal (pFDR $>0.05$ ) structural network measures and other behavioural measures (Table 5). Global structural characteristic path lengths were not significantly associated with any behavioural measures $(p>0.05)$.

\section{Discussion}

We applied both survey and experimental measures, and both functional and structural brain imaging, to assay brain-behaviour relationships in both social and nonsocial autistic trait dimensions. Various social and nonsocial measures correlated with both global functional and regional structural network efficiency, although the direction of these correlations was contrary to hypothesis: greater autistic traits tended to associate with greater efficiency. Where correlations were detected, more specific capacities such as systemising and theoryof-mind were related to structure of specific brain regions whereas general or integrative traits such as social responsiveness and attention orienting associated with 
Table 2 Spearman correlation coefficients between questionnaire/behavioural measures and global functional network measures

\begin{tabular}{|c|c|c|c|c|c|c|c|}
\hline Behavioural measure & $\begin{array}{l}\text { Clustering } \\
\text { coefficient } \\
\rho(p) \\
\end{array}$ & $\begin{array}{l}\text { Characteristic } \\
\text { path length } \\
\rho(p)\end{array}$ & $\begin{array}{l}\text { Efficiency } \\
\rho(p)\end{array}$ & $\begin{array}{l}\text { Behavioural } \\
\text { measure }\end{array}$ & $\begin{array}{l}\text { Clustering } \\
\text { coefficient } \\
\rho(p) \\
\end{array}$ & $\begin{array}{l}\text { Characteristic } \\
\text { path length } \\
\rho(p)\end{array}$ & $\begin{array}{l}\text { Efficiency } \\
\rho(p)\end{array}$ \\
\hline $2^{\circ} \mathrm{ToM}$ & $-0.121(0.257)$ & $0.087(0.321)$ & $\begin{array}{l}-0.202 \\
(0.142)\end{array}$ & $\begin{array}{l}\text { Reading the Mind in } \\
\text { the Eyes }\end{array}$ & $0.170(0.185)$ & $-0.220(0.119)$ & $\begin{array}{l}0.233 \\
(0.108)\end{array}$ \\
\hline Egocentric $1^{\circ} \mathrm{ToM}$ & $-0.030(0.445)$ & $-0.015(0.464)$ & $\begin{array}{l}-0.003 \\
(0.496)\end{array}$ & $\begin{array}{l}\text { Controlled Oral Word } \\
\text { Association }\end{array}$ & $-0.032(0.436)$ & $-0.024(0.448)$ & $\begin{array}{l}0.033 \\
(0.434)\end{array}$ \\
\hline Allocentric $1^{\circ} \mathrm{ToM}$ & $-0.036(0.430)$ & $0.017(0.468)$ & $\begin{array}{l}-0.006 \\
(0.492)\end{array}$ & Animal names & $-0.123(0.251)$ & $0.094(0.300)$ & $\begin{array}{l}-0.042 \\
(0.405)\end{array}$ \\
\hline AQ Soc & $0.308(0.053)$ & $-0.277(0.069)$ & $\begin{array}{l}0.277 \\
(0.071)\end{array}$ & Embedded figures & $-0.029(0.438)$ & $0.055(0.382)$ & $\begin{array}{l}0.039 \\
(0.419)\end{array}$ \\
\hline AQ Det & $-0.106(0.277)$ & $0.127(0.237)$ & $\begin{array}{l}-0.077 \\
(0.329)\end{array}$ & ANT alerting & $-0.202(0.142)$ & $0.100(0.304)$ & $\begin{array}{l}-0.206 \\
(0.136)\end{array}$ \\
\hline Empathy quotient & $-0.175(0.173)$ & $0.187(0.159)$ & $\begin{array}{l}-0.145 \\
(0.218)\end{array}$ & ANT orienting & $\begin{array}{l}-0.423 \\
(0.010)^{*}\end{array}$ & $0.441(0.007)^{*}$ & $\begin{array}{l}-0.406 \\
(0.013)^{*}\end{array}$ \\
\hline Systemizing quotient & $-0.006(0.488)$ & $0.021(0.459)$ & $\begin{array}{l}0.011 \\
(0.475)\end{array}$ & ANT conflict & $-0.095(0.313)$ & $0.170(0.186)$ & $\begin{array}{l}-0.115 \\
(0.275)\end{array}$ \\
\hline $\begin{array}{l}\text { Sensory Sensitivity } \\
\text { Questionnaire }\end{array}$ & $0.049(0.410)$ & $0.013(0.461)$ & $\begin{array}{l}0.008 \\
(0.491)\end{array}$ & ANT grand mean & $-0.002(0.488)$ & $0.028(0.427)$ & $\begin{array}{l}-0.017 \\
(0.458)\end{array}$ \\
\hline $\begin{array}{l}\text { Social } \\
\text { Responsiveness } \\
\text { Scale }\end{array}$ & $\begin{array}{l}0.455 \\
(0.0075)^{*}\end{array}$ & $-0.387(0.018)^{*}$ & $\begin{array}{l}0.467 \\
(0.006)^{*}\end{array}$ & & & & \\
\hline
\end{tabular}

function of anatomically distributed networks. This work incidentally shows that individual differences in theoryof-mind can be measured using reaction time differences from even small numbers of trials, and introduces a new perspective on the 'systemising' construct as the capacity to construct invariant contextual associations.

One non-social survey measure-the Systemizing Quotient-covaried with global structural network efficiency driven especially by medial temporal lobes, and one social experimental measure-theory-ofmind-covaried with nodal efficiency and clustering near right temporoparietal junction. One social cognitive survey measure-the SRS-and one non-social experimental measure-ANT orienting-covaried with global functional network efficiencies. AQSS and AQDet despite tapping a social communicative construct related to the SRS and an attentional construct related on face to the ANT, respectively, bore no significant relationship, and neither did sensory, perceptual, empathic or verbal measures. This pattern of results might have as much to do with the relatively well established validity of the SRS and the ANT as it might with any primacy of social responsiveness and attentional orienting, although the developmental relationship between these two constructs [81, 82] does not escape our notice.

The nodal functional results are less certain than the corresponding global results, because of two sources of variation that render fMRI-based network localisations inherently broad. First, functional connectivity studied across the entire brain emphasises widespread networks and not localised neighbourhoods, because the time series correlations on which it is based are essentially transitive, making the resulting connectivity graph a transitive closure: if, for example, supramarginal gyrus is functionally connected with orbitofrontal cortex, and orbitofrontal cortex is functionally connected with medial temporal lobe, then supramarginal gyrus will to some degree be functionally connected to medial temporal lobe. Second, functional maps at the population level are accurate only in broad strokes; individual differences in functional anatomical boundaries [83] imply that multiple functional subregions are collapsed into single anatomical parcels at the resolution of AAL-90, and thus that multiple functional relationships amongst these regions are likewise collapsed into single edges within any network graph. So it makes sense that the fMRI connectivity results highlight distributed networks associated with domain-general properties such as attentional orienting and a broad measure of social responsiveness.

Both in the case of attentional orienting and in the case of social cognition, these fMRI-based measures found brain networks to be physiologically more efficiently organised for individuals higher in autistic traits, even though high autistic traits mean that one is behaviourally less efficient at each of these cognitive skills, taking longer to orient attention and being less socially responsive. This disjunction between physiological and behavioural measures of efficiency can be interpreted in at least three ways: 
Table 3 Spearman correlation coefficients between Social Responsiveness Scale scores and nodal functional network measures

\begin{tabular}{|c|c|c|c|}
\hline Region & Nodal strength $\rho(p)$ & Nodal clustering $\rho(p)$ & Nodal efficiency $\rho(p)$ \\
\hline L precentral gyrus & & $0.442(0.008)$ & $0.452(0.006)$ \\
\hline R precentral gyrus & & $0.468(0.005)$ & $0.514(0.002)$ \\
\hline $\mathrm{L}$ superior frontal gyrus & & $0.549(0.001)$ & $0.523(0.001)$ \\
\hline L superior frontal (orbital) & $0.545(0.001)$ & $0.423(0.011)$ & $0.434(0.010)$ \\
\hline R superior frontal (orbital) & $0.558(0.0006)$ & $0.466(0.004)$ & $0.449(0.006)$ \\
\hline R middle frontal gyrus & & $0.510(0.003)$ & $0.510(0.002)$ \\
\hline L middle frontal (orbital) & $0.603(0.0004)$ & $0.636(0.0002)$ & $0.639(0.0002)$ \\
\hline R middle frontal (orbital) & $0.547(0.001)$ & $0.518(0.002)$ & $0.532(0.001)$ \\
\hline $\mathrm{L}$ inferior frontal (opercular) & & $0.382(0.020)$ & $0.413(0.013)$ \\
\hline R inferior frontal (triangular) & & $0.446(0.007)$ & $0.401(0.015)$ \\
\hline L inferior frontal (orbital) & & $0.440(0.007)$ & $0.434(0.009)$ \\
\hline R inferior frontal (orbital) & & $0.389(0.017)$ & \\
\hline L Rolandic operculum & & $0.397(0.015)$ & \\
\hline R Rolandic operculum & & $0.490(0.003)$ & $0.452(0.006)$ \\
\hline L supplementary motor area & $0.590(0.0006)$ & $0.366(0.023)$ & $0.449(0.007)$ \\
\hline L medial superior frontal gyrus & $0.510(0.003)$ & & \\
\hline L olfactory & & $0.396(0.017)$ & $0.437(0.008)$ \\
\hline R olfactory & & $0.355(0.027)$ & $0.365(0.025)$ \\
\hline R superior frontal gyrus (medial) & & $0.413(0.013)$ & $0.358(0.027)$ \\
\hline L superior frontal (medial orbital) & & & $0.362(0.024)$ \\
\hline R superior frontal (medial orbital) & & & $0.379(0.021)$ \\
\hline L insula & & $0.409(0.013)$ & $0.383(0.019)$ \\
\hline$R$ insula & & $0.377(0.020)$ & $0.351(0.029)$ \\
\hline $\mathrm{L}$ anterior cingulate, paracingulate & & & $0.368(0.022)$ \\
\hline $\mathrm{R}$ anterior cingulate, paracingulate & & $0.437(0.009)$ & $0.376(0.021)$ \\
\hline L median cingulate, paracingulate & & $0.560(0.0008)$ & $0.468(0.004)$ \\
\hline $\mathrm{L}$ posterior cingulate & & $0.368(0.024)$ & $0.386(0.020)$ \\
\hline R posterior cingulate & & $0.372(0.022)$ & \\
\hline R hippocampus & $0.576(0.001)$ & $0.410(0.011)$ & $0.345(0.030)$ \\
\hline L parahippocampal gyrus & & $0.405(0.012)$ & $0.337(0.030)$ \\
\hline R parahippocampal gyrus & & $0.431(0.008)$ & $0.412(0.011)$ \\
\hline L amygdala & & $0.449(0.006)$ & $0.415(0.013)$ \\
\hline R amygdala & $0.479(0.003)$ & $0.418(0.010)$ & $0.393(0.016)$ \\
\hline $\mathrm{L}$ calcarine cortex & & $0.483(0.003)$ & $0.461(0.005)$ \\
\hline R calcarine cortex & & $0.445(0.007)$ & $0.385(0.017)$ \\
\hline L cuneus & & $0.388(0.016)$ & $0.401(0.014)$ \\
\hline R cuneus & & $0.409(0.012)$ & $0.381(0.020)$ \\
\hline$L$ lingual gyrus & & $0.487(0.003)$ & $0.445(0.006)$ \\
\hline L superior occipital gyrus & & $0.464(0.005)$ & $0.492(0.002)$ \\
\hline L fusiform gyrus & & $0.356(0.026)$ & $0.363(0.022)$ \\
\hline R fusiform gyrus & & $0.413(0.012)$ & $0.408(0.012)$ \\
\hline L postcentral gyrus & & & $0.355(0.029)$ \\
\hline$R$ postcentral gyrus & & & $0.355(0.027)$ \\
\hline L inferior parietal lobule & & $0.492(0.003)$ & $0.433(0.010)$ \\
\hline
\end{tabular}


Table 3 Spearman correlation coefficients between Social Responsiveness Scale scores and nodal functional network measures (Continued)

\begin{tabular}{|c|c|c|c|}
\hline Region & Nodal strength $\rho(p)$ & Nodal clustering $\rho(p)$ & Nodal efficiency $\rho(p)$ \\
\hline R inferior parietal lobule & & $0.356(0.028)$ & $0.393(0.017)$ \\
\hline L supramarginal gyrus & $0.478(0.004)$ & $0.403(0.014)$ & $0.417(0.011)$ \\
\hline R supramarginal gyrus & & $0.479(0.004)$ & $0.443(0.007)$ \\
\hline $\mathrm{L}$ angular gyrus & $0.572(0.0006)$ & $0.457(0.006)$ & $0.511(0.003)$ \\
\hline $\mathrm{R}$ angular gyrus & & $0.448(0.007)$ & $0.445(0.007)$ \\
\hline L precuneus & & $0.617(0.0002)$ & $0.567(0.001)$ \\
\hline R precuneus & & $0.374(0.023)$ & $0.359(0.026)$ \\
\hline L paracentral lobule & & & $0.374(0.021)$ \\
\hline R paracentral lobule & & $0.419(0.011)$ & \\
\hline L putamen & & $0.369(0.023)$ & \\
\hline R putamen & & $0.587(0.0004)$ & $0.550(0.0008)$ \\
\hline L pallidum & & $0.486(0.004)$ & $0.444(0.008)$ \\
\hline R pallidum & $0.649(0.0001)$ & $0.366(0.021)$ & \\
\hline R lenticular nucleus, pallidum & & & $0.357(0.026)$ \\
\hline$L$ thalamus & & & $0.358(0.026)$ \\
\hline L Heschl's gyrus & & $0.363(0.022)$ & $0.354(0.027)$ \\
\hline L superior temporal pole & & $0.499(0.003)$ & $0.444(0.007)$ \\
\hline R superior temporal pole & & $0.354(0.029)$ & $0.365(0.023)$ \\
\hline $\mathrm{L}$ middle temporal gyrus & $0.503(0.003)$ & $0.459(0.007)$ & $0.473(0.005)$ \\
\hline L middle temporal pole & & $0.451(0.007)$ & $0.399(0.015)$ \\
\hline $\mathrm{R}$ middle temporal pole & & $0.466(0.006)$ & $0.392(0.016)$ \\
\hline $\mathrm{R}$ inferior temporal & $0.578(0.0007)$ & $0.417(0.010)$ & $0.417(0.011)$ \\
\hline
\end{tabular}

(1) Despite the deficits in these two specific behavioural measures, autistic traits can make people more efficient at other aspects of cognition. This scenario is easy to imagine and is enunciated in Asperger's absent-minded "Professor" whose "besonderen Leistungen" ("unusual achievements") come hand in hand with "Hilflosigkeit dem praktischen Leben gegenüber" ("helplessness in the face of practical life") [84], a trope repeated time and again in postmodern literature and media (e.g. [85], p. 6). In terms of neural and cognitive mechanisms, a perturbed excitatory/inhibitory balance [86] produces abnormally low network entropy [87] which when it arises during activity-dependent development evokes abnormal desegregation between networks [88, 89] consistent with the observation of enhanced 'rich club' connectivity of network hubs in autism $[6,90]$. The cognitive result can be temporally inefficient orienting [91] and spatially inefficient filtering [92]. This 'sticky' style of attention may lead to rumination on particular stimuli and details, and to compensatory processing [93] that yields ultimately a more complete style of representation based on bricolage [40]; likewise, time and cognitive effort not spent on exhausting and often futile attempts at social understanding may instead be invested in understanding the more tractable world of deterministic systems and rules.

(2) fMRI-based connectivity may measure a crude combination of connectivities within anatomically superimposed functional networks that differ in fMRI-indistinguishable parameters such as operating frequency band and cellular physiology. Previous studies of eyes-closed resting EEG taken together show, if nothing else, that the picture of autistic brain connectivity becomes complicated when frequency band is taken into account. Findings include elevated short-range coherence in the theta band and reduced long-range coherence in the lower-alpha band [94], elevated short-range and reduced long-range coherence in delta band correlating with score on the Autism Diagnostic Observation Schedule (ADOS) [73], and reduced delta and theta coherences at all ranges with reduced alpha and beta coherences at some short-range electrode pairs [95]. An eyes-open resting MEG study measuring graph-theoretic relations amongst correlations between signal envelopes in a variety of frequency 
Table 4 Spearman correlation coefficients between Attention Network Test orienting scores and nodal functional clustering coefficients

\begin{tabular}{|c|c|}
\hline Regions & $\begin{array}{l}\text { Clustering coefficient } \\
\rho(p)\end{array}$ \\
\hline R precentral gyrus & $-0.511(0.003)$ \\
\hline L superior frontal & $-0.417(0.010)$ \\
\hline L middle frontal (orbital) & $-0.480(0.004)$ \\
\hline R middle frontal (orbital) & $-0.431(0.009)$ \\
\hline L inferior opercular frontal & $-0.412(0.012)$ \\
\hline R olfactory & $-0.450(0.006)$ \\
\hline R middle orbitofrontal & $-0.429(0.007)$ \\
\hline$R$ gyrus rectus & $-0.439(0.008)$ \\
\hline $\mathrm{L}$ amygdala & $-0.485(0.003)$ \\
\hline R amygdala & $-0.479(0.004)$ \\
\hline R calcarine cortex & $-0.553(0.0008)$ \\
\hline L superior occipital gyrus & $-0.445(0.006)$ \\
\hline $\mathrm{R}$ postcentral gyrus & $-0.434(0.007)$ \\
\hline $\mathrm{R}$ inferior parietal lobule & $-0.481(0.004)$ \\
\hline R supramarginal gyrus & $-0.571(0.001)$ \\
\hline L putamen & $-0.437(0.006)$ \\
\hline R putamen & $-0.480(0.003)$ \\
\hline L pallidum & $-0.471(0.004)$ \\
\hline R pallidum & $-0.434(0.010)$ \\
\hline L superior temporal pole & $-0.424(0.009)$ \\
\hline $\mathrm{L}$ middle temporal pole & $-0.494(0.003)$ \\
\hline $\mathrm{R}$ middle temporal pole & $-0.455(0.005)$ \\
\hline
\end{tabular}

All results are significant at 5\% FDR level

bands found greater gamma network efficiency but lesser beta efficiency in autism, both categorically and in correlation with ADOS scores, along with greater alpha efficiency categorically [96]; these authors suggested an altered balance between heightened bottom-up, gamma-mediated signalling and attenuated top-down, beta-mediated signalling [97]. Both EEG [98] and intracranial [99] recordings in humans have demonstrated that BOLD fMRI is most positively coupled to gamma oscillations. Viewed through this lens, then, our fMRI connectivity data become consistent with the thesis of heightened bottom-up, gamma-mediated connectivity not only in autism categorically but perhaps also with autistic traits dimensionally. This second case of interpretation is not at all mutually exclusive with the first case above; indeed, such an altered balance between bottom-up and top-down information flow could be the physiological substrate of autistic cognitive superiorities and deficits.

(3) There may be a discontinuity between clinically autistic impairment on the one hand and subclinical levels of nominally 'autistic' traits that form part of general individual differences on the other. Autistic traits in separate domains of cognitive function tend to be inherited largely independently $[100,101]$ and constitute distinct domains of function in the nonautistic population [102], but once they cross watershed levels they may begin to synergise, reinforcing each other as development proceeds [19]. The result might be a classic inverted-U dose-response curve: traits that individually and in moderate doses are cognitively adaptive may in combination and in higher doses become cognitively impairing overall, as development proceeds. Indeed, DTI-based imaging shows that local nodal network inefficiency manifests as early as 6 months of age in familially high-risk infants who later are diagnosed with autism, progressing from right primary auditory and middle and superior temporal gyri to higher-order cortices [103].

Perhaps related to this third possibility of discontinuity across the diagnostic boundary is the current result's place within a mixed bag of previous findings: both functional [28] and structural [30] imaging studies have identified reduced average nodal resting-state functional network efficiency as a function of autistic traits in nonautistic adults [28], driven by inefficiencies in the default-mode network centred on posterior cingulum. However, structural imaging in categorically autistic children shows the opposite relationship, heightened efficiency with increasing autism severity [30]. Studies of autistic traits and simple functional connectivity, not deriving network metrics, have found mixed results in which autistic traits are related to lesser functional connectivity between a rostral anterior cingulate region of interest and bilateral mid-insula [29] but greater functional connectivities between the same region of interest and other insular subregions $[29,104]$ as well as lateral occipital cortex, superior parietal cortex and angular gyrus [29], and perhaps developmentally related to lesser connectivity within the default-mode network centred on posterior cingulum [104]. One study identified opposite occipitofrontal connectivity perturbations in two subgroups [105]. To the extent that this collection of methods and results can support any general conclusion about functional network characteristics and autistic traits, that conclusion seems the negative one that this relationship is not necessarily monotonic across the autism diagnostic boundary and/or across development, and that these dependencies may differ between brain networks. Indeed, recent theoretical work points out that in this context of normal individual differences in cognition, so-called 'autistic' trait dimensions, defined so generally as to encompass much individual cognitive 


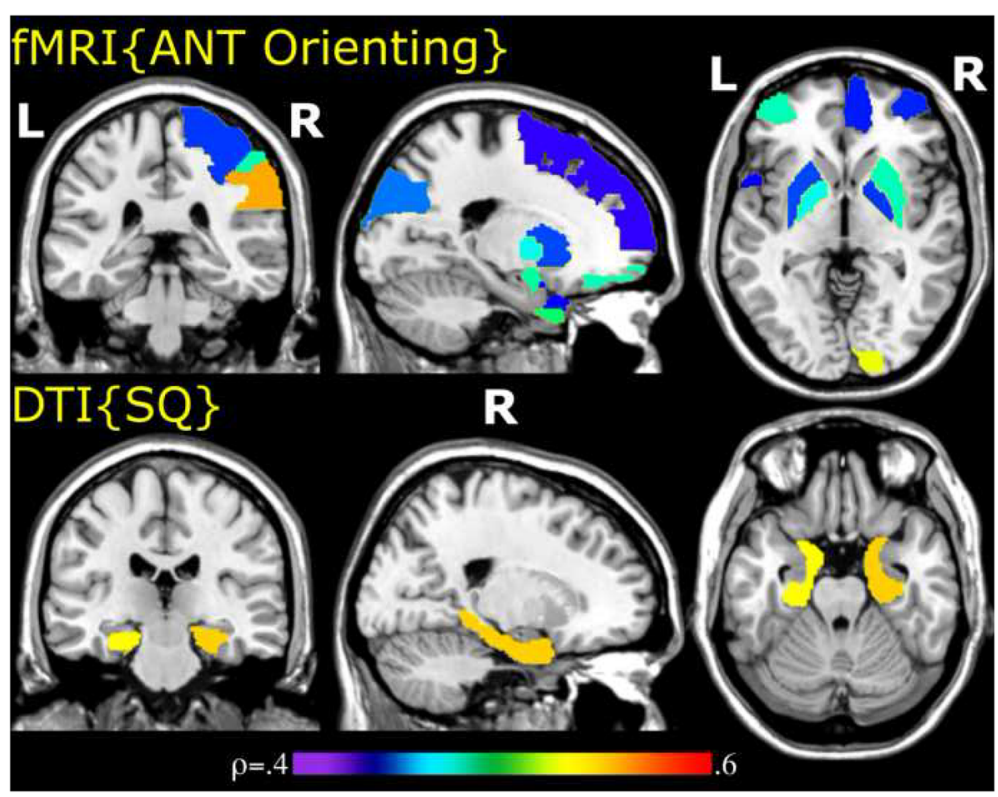

Fig. 1 Examples of functional and structural, experimental and survey results. Regional correlations between nodal functional network efficiencies and Attention Network Test orienting scores (top), and between nodal structural network clustering coefficients and Systemizing Quotient scores (bottom). Sizes of the regions reflect of AAL-90 parcellations and are not individually any indication of network extents. Orienting is associated with a functional attention network comprising basal ganglia and frontal, parietal and visual cortices, overlapping substantially with that for social responsiveness (not shown), whereas systemising is associated with structural contextual-association networks within parahippocampal cortices. Right supramarginal gyrus, the cortical region most strongly associated with attention orienting functionally, also is the region associated with theory-of-mind structurally

Table 5 Spearman correlation coefficients between questionnaire/behavioural measures and global structural network measures

\begin{tabular}{|c|c|c|c|c|c|c|c|}
\hline $\begin{array}{l}\text { Behavioural } \\
\text { measures }\end{array}$ & $\begin{array}{l}\text { Clustering } \\
\text { coefficient } \\
\rho(p) \\
\end{array}$ & $\begin{array}{l}\text { Characteristic } \\
\text { path length } \\
\rho(p)\end{array}$ & $\begin{array}{l}\text { Efficiency } \\
\rho(p)\end{array}$ & $\begin{array}{l}\text { Behavioural } \\
\text { measures }\end{array}$ & $\begin{array}{l}\text { Clustering } \\
\text { coefficient } \\
\rho(p) \\
\end{array}$ & $\begin{array}{l}\text { Characteristic } \\
\text { path length } \\
\rho(p)\end{array}$ & $\begin{array}{l}\text { Efficiency } \\
\rho(p)\end{array}$ \\
\hline $2^{\circ} \mathrm{ToM}$ & $0.127(0.248)$ & $-0.051(0.394)$ & $\begin{array}{l}0.144 \\
(0.218)\end{array}$ & $\begin{array}{l}\text { Reading the Mind in } \\
\text { the Eyes }\end{array}$ & $-0.162(0.195)$ & $0.210(0.135)$ & $\begin{array}{l}-0.141 \\
(0.229)\end{array}$ \\
\hline Allocentric $1^{\circ} \mathrm{ToM}$ & $-0.266(0.076)$ & $0.216(0.130)$ & $\begin{array}{l}-0.280 \\
(0.065)\end{array}$ & $\begin{array}{l}\text { Controlled Oral Word } \\
\text { Association }\end{array}$ & $-0.079(0.333)$ & $0.114(0.273)$ & $\begin{array}{l}-0.073 \\
(0.349)\end{array}$ \\
\hline Egocentric $1^{\circ} \mathrm{ToM}$ & $-0.205(0.137)$ & $0.149(0.216)$ & $\begin{array}{l}-0.169 \\
(0.181)\end{array}$ & Animal names & $0.077(0.342)$ & $-0.005(0.487)$ & $\begin{array}{l}0.154 \\
(0.207)\end{array}$ \\
\hline AQ Soc & $-0.104(0.295)$ & $0.136(0.235)$ & $\begin{array}{l}-0.115 \\
(0.273)\end{array}$ & Embedded figures & $-0.088(0.314)$ & $-0.002(0.498)$ & $\begin{array}{l}-0.076 \\
(0.335)\end{array}$ \\
\hline AQ Det & $-0.067(0.366)$ & $0.107(0.288)$ & $\begin{array}{l}-0.063 \\
(0.372)\end{array}$ & ANT alerting & $0.003(0.495)$ & $0.056(0.379)$ & $\begin{array}{l}0.043 \\
(0.415)\end{array}$ \\
\hline Empathy quotient & $0.221(0.124)$ & $-0.235(0.106)$ & $\begin{array}{l}0.213 \\
(0.131)\end{array}$ & ANT orienting & $0.152(0.210)$ & $-0.164(0.196)$ & $\begin{array}{l}0.152 \\
(0.206)\end{array}$ \\
\hline $\begin{array}{l}\text { Systemizing } \\
\text { quotient }\end{array}$ & $0.368(0.023)^{*}$ & $-0.256(0.090)$ & $\begin{array}{l}0.385 \\
(0.018)^{*}\end{array}$ & ANT conflict & $-0.052(0.396)$ & $-0.041(0.410)$ & $\begin{array}{l}-0.068 \\
(0.365)\end{array}$ \\
\hline $\begin{array}{l}\text { Sensory Sensitivity } \\
\text { Questionnaire }\end{array}$ & $0.156(0.202)$ & $-0.242(0.097)$ & $\begin{array}{l}0.107 \\
(0.286)\end{array}$ & ANT grand mean & $0.293(0.211)$ & $-0.283(0.196)$ & $\begin{array}{l}0.301 \\
(0.207)\end{array}$ \\
\hline $\begin{array}{l}\text { Social Responsiveness } \\
\text { Scale }\end{array}$ & $0.207(0.128)$ & $-0.175(0.168)$ & $\begin{array}{l}0.219 \\
(0.116)\end{array}$ & & & & \\
\hline
\end{tabular}

${ }^{*} p<0.05$ 
Table 6 Spearman correlation coefficients between Systemizing Quotient (SQ) scores and nodal structural network measures

\begin{tabular}{llllll}
\hline Regions & $\begin{array}{l}\text { Strength vs SQ } \\
\boldsymbol{\rho}(\boldsymbol{p})\end{array}$ & Regions & $\begin{array}{l}\text { Clustering coefficient vs SQ } \\
\boldsymbol{\rho}(\boldsymbol{p})\end{array}$ & Regions & $\begin{array}{l}\text { Efficiency vs SQ } \\
\boldsymbol{\rho}(\boldsymbol{p})\end{array}$ \\
\hline L Parahippocampal & $0.585(0.0003)$ & R Parahippocampal & $0.556(0.0007)$ & L Parahippocampal & $0.556(0.001)$ \\
R Parahippocampal & $0.592(0.0004)$ & R Middle temporal pole & $0.517(0.0013)$ & R Parahippocampal & $0.564(0.0005)$ \\
R Olfactory & $0.555(0.0007)$ & & & & \\
\hline
\end{tabular}

All results are significant at 5\% FDR level

variation, may well be influenced by mechanisms distinct from those that produce the syndrome of autism [11].

Our DTI data, in contrast to fMRI, offer by their nature a more granular description of connectivity, highlighting specific anatomical nodes of convergence associated with contextual association (tapped by the Systemizing Quotient) and theory-of-mind in particular. In this analysis, greater network integrity of a functional brain region reflects greater ability within the corresponding domain of cognitive function, regardless of whether such ability maps onto greater or lesser levels of autistic traits.

It seems especially notable that this analysis confirms right supramarginal gyrus in particular as a driver of faster perspective-taking, a result consistent with experimental evidence relating the right temporoparietal junction to allocentric perspective-taking [106] and attribution of mental states [31]; the posterior inferior extent of this AAL-90 region is consistent with the localisation of theory-of-mind activations [107], although an analysis in individual subject space could provide more specific anatomical confirmation. Likewise notable is the absence, within these functional and structural graph measures, of any association of right supramarginal gyrus with the RMET, contrary to the case of simple correlative analysis with task-based fMRI [108].

Interpretation of the SQ's bilateral medial temporal localisation is complicated by the persistent ambiguity as to what skill or trait it is that the SQ is measuring [39], although we have argued (vide supra) that the SQ measures invariant contextual association. Like the slowed attentional orienting discussed above, invariant contextual association can be straightforwardly associated with autistic bricolage, the building up of configural representations from their component parts and details. And indeed contextual association in general has been proposed $[109,110]$ as a parsimoniously unifying theme for parahippocampal cortex's functional associations with mapping and navigation as well as episodic memory, all skills associated with autism. The computational structure of the medial temporal lobe can support representations of spatial, temporal, and conceptual distances and contexts [111]; autistic differences in synaptic strengths might bias hippocampal firing sequences towards representation of short distances, producing a knack for local detail.

\section{Limitations}

Interpretation of these relationships between brain connectivity and behavioural measures is complicated many meanings of the term 'connectivity' [88, 112], referring variously to functional connectivity (correlated time series), anatomical connectivity (tracts and synapses) and computational connectivity (mutual information), on multiple spatial and temporal scales. Indeed, the question of connectivity differences in autistic versus nonautistic brains, or in this case as a function of individual differences in autistic traits, depends at least as much on what we look for and how we look for it as it does on what we are looking at.

Individual functional mapping both of task-related activations within delimited brain areas [113] and of resting-state network correlations across the whole brain [83] shows that individual functional anatomical boundaries are idiosyncratic, and anatomically neighbouring functions are interdigitated when examined on spatial scales finer that gyral and sulcal definitions [83]. Any study that bases and expresses its localisations in terms of central tendencies across individuals, then, can yield only approximate results. Nevertheless, such results do retain an approximate meaning because functional anatomical adjacencies and parallel connections are preserved across individuals, even though their geometric details are not [83]. In terms of the current study, even though a particular AAL-90 parcel will in general include more than a single functional brain region, at a population (and sample) level, this blurring of several individual functional anatomies into each AAL-90 parcel does not impair power to make inferences about the functional anatomical neighbourhood of that parcel (e.g., [114-116]), and to support hypotheses that localise a functional region wholly or probabilistically to a particular parcel, e.g. theory-of-mind whose right temporoparietal hypothesis falls within AAL-90's right supramarginal gyrus parcel.

No matter how powerful the physiological assays, brain-behaviour correlations can be only as sensitive and specific as the behavioural measures are. Of especial relevance to this current work, quantitative assessment of sensory sensitivity remains a developing endeavour, in 
which survey reports such as the SSQ may not converge with direct observations [117]. Likewise, the story surrounding FC-EFT and EFT variants in general as a measure of autistic perceptual focus on detail has become more and more equivocal [54], and the RMET seems to accomplish its correlation with autistic traits more by measuring verbal skills than by measuring empathy per se [50,51].

\section{Conclusions}

This study associates more autistotypal (i.e. more impaired) levels of social responsiveness and attention orienting with greater efficiency of brain-wide functional networks, and greater levels of systemising and of social perspective-taking with greater structural network efficiencies centring on medial/anterior temporal lobe and right temporoparietal junction, respectively. The skills indexed by widespread functional network efficiency may be more general across social and non-social domains of cognition, and those indexed by anatomically specific structural network efficiency more domain-specific. This study has not investigated intra-individual variation in the momentto-moment dynamics of functional brain connectivity $[118,119]$, an approach that in future may help to resolve apparent inconsistencies between these and other early results on dimensional relationships between autistic traits and neural connectivity. Further work can complement the current results with EEG or MEG imaging modalities sensitive to highfrequency signals and can resolve the open questions of whether these relationships between autistic traits and brain network efficiencies are invariant across development, and across the diagnostic boundary between autistic traits and autism spectrum conditions. Understanding how people with autistic traits think can ultimately help inform individualised supports for people within and beyond the autism spectrum.

\section{Supplementary Information}

The online version contains supplementary material available at https://doi. org/10.1186/s13229-020-00377-8.

Additional file 1. Behavioural data. Spreadsheet of behavioural data for all subjects; and log data from each subject's theory-of-mind test, in raw (ExperimentLog.txt) and tabular (.csv) formats.

Additional file 2. Structural images 1-7. Anonymised T1 structural images for subjects 1 to 7 , in gzipped NIfTI format.

Additional file 3. Structural images 8-14. Anonymised T1 structural images for subjects 8 to 14, in gzipped NIfTI format.

Additional file 4. Structural images 15-21. Anonymised T1 structural images for subjects 15 to 21, in gzipped NIfTI format.

Additional file 5. Structural images 22-27. Anonymised T1 structural images for subjects 22 to 27 , in gzipped NIfTI format.
Additional file 6. Structural images 28-30. Anonymised T1 structural images for subjects 28, 29, and 30, in gzipped NIfTI format.

Additional file 7. Nuisance regressors. Nuisance regressor time series for each subject, as floating-point values in ASCII text format.

Additional file 8. Connectivity matrices. Connection matrices and functional correlation matrices for each subject, as floating-point values in ASCll text format, and MATLAB code for producing these.

Additional file 9. Brain-behaviour correlations. README file detailing data curation; AAL-90 region masks in NIfTI format; spreadseehts of Spearman correlations; code and data for the correlational analysis.

Additional file 10: Supplementary Methods. Theory-of-Mind Measurement.

\section{Acknowledgements}

The study was designed and the data collected in 2011 whilst SP, AA, RM, PKR and MKB were at the National Brain Research Centre, Manesar, India. This study was presented in part at the annual meeting of the International Society for Autism Research, Montréal, on 2 May 2019.

\section{Authors' contributions}

MKB, PKR, SP and AA conceived and designed the study. RM administered IQ tests; AA collected the other behavioural data. DV performed data cleaning and prepared derived data for the theory-of-mind behavioural paradigm. SP collected and analysed the brain imaging data and the brain-behaviour correlations. MKB, AA and SP wrote the paper. The authors read and approved the final manuscript.

\section{Authors' information \\ AA and SP contributed equally to this work.}

\section{Funding}

Development of the video game software was supported by an agreement with Cornell University, Department of Human Development under Faculty Early Career Development Award BCS-0846892 from the Directorate for Social, Behavioral and Economic Sciences, US National Science Foundation, awarded to MKB.

\section{Availability of data and materials}

Pseudonymised behavioural data and brain-behaviour correlations will be made available as supplementary files alongside this manuscript. Ethical permission and consent do not allow for sharing individual subjects' fMRI and DTI brain images.

\section{Ethics approval and consent to participate}

The study was conducted following the guidelines provided in the Declaration of Helsinki and was approved by the National Brain Research Centre institutional human ethics committee. Informed consent was obtained prior to psychometric and MRI data collection.

\section{Consent for publication}

Not applicable.

\section{Competing interests}

The authors declare that they have no competing interests.

\section{Author details}

${ }^{1} M$ MIND Research Network, 1101 Yale Blvd NE, Albuquerque, NM 87106, USA. ${ }^{2}$ National Brain Research Centre, NH-8, Nainwal Mode, Manesar 122051, India. ${ }^{3}$ Centre for Cognitive Neuroscience, Universität Salzburg, Kapitelgasse 4-6, 5020 Salzburg, Austria. ${ }^{4}$ National Institute of Mental Health and Neuro Sciences, Hosur Road, Bangalore 560029, India. ${ }^{5}$ Department of Psychology, University of Oslo, Harald Schjelderups hus, Forskningsveien 3A, 0373 Oslo, Norway. ${ }^{6}$ Department of Psychology, Chaucer Bldg., Nottingham Trent University, Shakespeare Street, Nottingham NG1 4FQ, UK. ' School of Biomedical Engineering, Indian Institute of Technology (Banaras Hindu University), Varanasi 221005, India. ${ }^{8}$ The Com DEALL Trust, 224, 6th 'A' Main Road, near Specialist Hospital, 2nd Block, HRBR Layout, Bangalore 560043, India. 
Received: 26 December 2019 Accepted: 2 September 2020 Published online: 21 January 2021

\section{References}

1. Crespi B, Dinsdale N, Read S, Hurd P. Spirituality, dimensional autism, and schizotypal traits: the search for meaning. PLoS One. 2019;14(3):e0213456. https://doi.org/10.1371/journal.pone.0213456.

2. van den Heuvel OA, Remijnse PL, Mataix-Cols D, Vrenken H, Groeneweg HJ. The major symptom dimensions of obsessive-compulsive disorder are mediated by partially distinct neural systems. Brain. 2009;132(4):853-68. https://doi.org/10.1093/brain/awn267.

3. Nelson MT, Seal ML, Phillips LJ, Merritt AH, Wilson R, Pantelis C. An investigation of the relationship between cortical connectivity and schizotypy in the general population. J Nerv Ment Dis. 2011;199(5):348-53. https://doi.org/10.1097/NMD.0b013e318217514b.

4. Wang Y, Yan C, Yin DZ, Fan MX, Cheung EF, Pantelis C, Chan RC. Neurobiological changes of schizotypy: Evidence from both volume-based morphometric analysis and resting-state functional connectivity. Schizophr Bull. 2015;41(Suppl 2):S444-54. https://doi.org/10.1093/schbul/sbu178.

5. Müller R-A, Shih P, Keehn B, Deyoe JR, Leyden KM, Shukla DK. Underconnected, but how? A survey of functional connectivity MRI studies in autism spectrum disorders. Cereb Cortex. 2011;21(10):2233-43. https://doi.org/10.1093/cercor/bhq296.

6. Keown CL, Datko MC, Chen CP, Maximo JO, Jahedi A, Müller R-A. Network organization is globally atypical in autism: a graph theory study of intrinsic functional connectivity. Biol Psychiatry Cogn Neurosci Neuroimaging. 2017; 2(1):66-75. https://doi.org/10.1016/j.bpsc.2016.07.008.

7. Abbott AE, Nair A, Keown CL, Datko M, Jahedi A, Fishman I, Müller RA Patterns of atypical functional connectivity and behavioral links in autism differ between default, salience, and executive networks. Cereb Cortex. 2016;26(10):4034-45. https://doi.org/10.1093/cercor/bhv191.

8. Elton A, Di Martino A, Hazlett HC, Gao W. Neural connectivity evidence for a categorical-dimensional hybrid model of autism spectrum disorder. Biol Psychiatry. 2016;80(2):120-8. https://doi.org/10.1016/j.biopsych.2015.10.020

9. Johnson $\mathrm{MH}$, Halit H, Grice SJ, Karmiloff-Smith A. Neuroimaging of typical and atypical development: a perspective from multiple levels of analysis. Dev Psychopathol. 2002;14(3):521-36. https://doi.org/10.1017/ s0954579402003073.

10. Johnson $\mathrm{MH}$. Interactive specialization: a domain-general framework for human functional brain development? Dev Cogn Neurosci. 2011;1(1):7-21. https://doi.org/10.1016/j.den.2010.07.003.

11. Mottron L, Bzdok D. Autism spectrum heterogeneity: fact or artifact? Mol Psychiatry. 2020; in press. https://doi.org/10.1038/s41380-020-0748-y.

12. Constantino JN, Todd RD. Intergenerational transmission of subthreshold autistic traits in the general population. Biol Psychiatry. 2005;57(6):655-60. https://doi.org/10.1016/j.biopsych.2004.12.014.

13. Warnell KR, Redcay E. Minimal coherence among varied theory of mind measures in childhood and adulthood. Cognition. 2019;191:103997. https://doi.org/10.1016/j.cognition.2019.06.009

14. White SJ, Coniston D, Rogers R, Frith U. Developing the Frith-Happé animations: a quick and objective test of Theory of Mind for adults with autism. Autism Res. 2011;4(2):149-54. https://doi.org/10.1002/aur.174.

15. Brewer N, Young RL, Barnett E. Measuring theory of mind in adults with autism spectrum disorder. J Autism Dev Disord. 2017;47(7):1927-41. https://doi.org/10.1007/s10803-017-3080-x.

16. Apperly IA, Warren F, Andrews BJ, Grant J, Todd S. Developmental continuity in theory of mind: speed and accuracy of belief-desire reasoning in children and adults. Child Dev. 2011;82(5):1691-703. https://doi.org/10. 1111/j.1467-8624.2011.01635.x.

17. Yoder KJ, Belmonte MK. Combining computer game-based behavioural experiments with high-density EEG and infrared gaze tracking. J Vis Exp. 2010;46:e2320. https://doi.org/10.3791/2320.

18. Valla JM, Ganzel BL, Yoder KJ, Chen GM, Lyman LT, Sidari AP, Keller AE, Maendel JW, Perlman JE, Wong SKL, Belmonte MK. More than maths and mindreading: sex differences in empathising/systemising covariance. Autism Res. 2010;3(4):174-84. https://doi.org/10.1002/aur.143.

19. Valla JM, Belmonte MK. Detail-oriented cognitive style and social communicative deficits, within and beyond the autism spectrum: independent traits that grow into developmental interdependence. Dev Rev. 2013;33(4):371-98. https://doi.org/10.1016/j.dr.2013.08.004.
20. Ronald A, Happé F, Plomin R. The genetic relationship between individual differences in social and nonsocial behaviours characteristic of autism. Dev Sci. 2005;8(5):444-58. https://doi.org/10.1111/j.1467-7687.2005.00433.x.

21. Ronald A, Happé F, Bolton P, Butcher LM, Price TS, Wheelwright S, BaronCohen S, Plomin R. Genetic heterogeneity between the three components of the autism spectrum: a twin study. J Am Acad Child Adolesc Psychiatry. 2006;45(6):691-9. https://doi.org/10.1097/01.chi.0000215325.13058.9d.

22. Warrier V, Toro R, Won H, Leblond CS, Cliquet F, Delorme R, De Witte W, Bralten J, Chakrabarti B, Børglum AD, Grove J, Poelmans G, Hinds DA, Bourgeron T, Baron-Cohen S. Social and non-social autism symptoms and trait domains are genetically dissociable. Commun Biol. 2019:2:328. https://doi.org/10.1038/s42003-019-0558-4.

23. Bullmore ET, Sporns O. Complex brain networks: graph theoretical analysis of structural and functional systems. Nat Rev Neurosci. 2009;10(3):186-98. https://doi.org/10.1038/nrn2575.

24. Hagmann P, Cammoun L, Gigandet X, Meuli R, Honey CJ, Wedeen VJ, Sporns O. Mapping the structural core of human cerebral cortex. PLoS Biol. 2008;6(7):e159. https://doi.org/10.1371/journal.pbio.0060159.

25. Otte WM, van Diessen E, Paul S, Ramaswamy $R$, Subramanyam Rallabandi VP, Stam CJ, Roy PK. Aging alterations in whole-brain networks during adulthood mapping with the minimum spanning tree indices: The interplay of density, connectivity cost and life-time trajectory. Neurolmage. 2015;109: 171-89. https://doi.org/10.1016/j.neuroimage.2015.01.011.

26. Van Dijk KRA, Hedden T, Venkataraman A, Evans KC, Lazar SW, Buckner RL. Intrinsic functional connectivity as a tool for human connectomics: theory, properties, and optimization. J Neurophysiol. 2010;103(1):297-321. https://doi.org/10.1152/jn.00783.2009.

27. Rubinov M, Sporns O. Complex network measures of brain connectivity: uses and interpretations. Neurolmage. 2010;52(3):1059-69. https://doi.org/ 10.1016/j.neuroimage.2009.10.003.

28. Jakab A, Emri M, Spisak T, Szeman-Nagy A, Beres M, Kis SA, Molnar P, Berenyi E. Autistic traits in neurotypical adults: correlates of graph theoretical functional network topology and white matter anisotropy patterns. PLoS One. 2013;8(4):e60982. https://doi.org/10.1371/journal.pone. 0060982.

29. Di Martino A, Shehzad Z, Kelly C, Krain Roy K, Gee DG, Uddin LQ, Gotimer K Klein DF, Castellanos FX, Milham MP. Relationship between cingulo-insular functional connectivity and autistic traits in neurotypical adults. Am J Psychiatr. 2009;166(8):891-9. https://doi.org/10.1176/appi.ajp.2009.08121894.

30. Billeci L, Calderoni S, Conti E, Lagomarsini A, Narzisi A, Gesi C, Carmassi C, Dell'Osso L, Cioni G, Muratori F, Guzzetta A. Brain network organization correlates with autistic features in preschoolers with autism spectrum disorders and in their fathers: preliminary data from a DWI analysis. J Clin Med. 2019;8(4):e487. https://doi.org/10.3390/jcm8040487.

31. Saxe $R$, Wexler A. Making sense of another mind: the role of the right temporo-parietal junction. Neuropsychologia. 2005;43(10):1391-9. https://doi.org/10.1016/j.neuropsychologia.2005.02.013.

32. Fan J, McCandliss BD, Fossella J, Flombaum Jl, Posner MI. The activation of attentional networks. Neurolmage. 2005:26(2):471-9. https://doi.org/10.1016/ j.neuroimage.2005.02.004.

33. Fan J, Bernardi S, Dam NT, Anagnostou E, Gu X, Martin L, Park Y, Liu X, Kolevzon A, Soorya L, Grodberg D, Hollander E, Hof PR. Functional deficits of the attentional networks in autism. Brain Behav. 2012;2(5):647-60. https://doi.org/10.1002/brb3.90.

34. Sassa Y, Taki Y, Takeuchi H, Hashizume H, Asano M, Asano K, Wakabayashi A, Kawashima R. The correlation between brain gray matter volume and empathizing and systemizing quotients in healthy children. Neurolmage. 2012;60(4):2035-41. https://doi.org/10.1016/j.neuroimage.2012.02.021.

35. Baron-Cohen S, Wheelwright S, Skinner R, Martin J, Clubley E. The AutismSpectrum Quotient (AQ): evidence from Asperger syndrome/highfunctioning autism, males and females, scientists and mathematicians. J Autism Dev Disord. 2001;31(1):5-17. https://doi.org/10.1023/a: 1005653411471

36. Baron-Cohen S, Wheelwright S. The Empathy Quotient: an investigation of adults with Asperger syndrome or high functioning autism, and normal sex differences. J Autism Dev Disord. 2004;34(2):163-75. https://doi.org/10.1023/ b:jadd.0000022607.19833.00.

37. Baron-Cohen S, Richler J, Bisarya D, Gurunathan N, Wheelwright S. The Systemizing Quotient: an investigation of adults with Asperger syndrome or high functioning autism, and normal sex differences. Philos Trans R Soc B. 2003;358(1430):361-74. https://doi.org/10.1098/rstb.2002.1206. 
38. Morsanyi K, Primi C, Handley SJ, Chiesi F, Galli S. Are systemizing and autistic traits related to talent and interest in mathematics and engineering? Testing some of the central claims of the empathizing-systemizing theory. Br J Psychol. 2012;103(4):472-96. https://doi.org/10.1111/j.2044-8295.2011. 02089.x

39. Ling J, Burton TC, Salt JL, Muncer SJ. Psychometric analysis of the Systemizing Quotient (SQ) scale. Br J Psychol. 2009;100(3):539-52. https://doi.org/10.1348/000712608X368261.

40. Belmonte MK. Does the experimental scientist have a 'theory of mind'? Rev Gen Psychol. 2008;12(2):192-204. https://doi.org/10.1037/1089-2680. 12.2.192.

41. Greenberg DM, Warrier V, Allison C, Baron-Cohen S. Testing the empathizing-systemizing theory of sex differences and the extreme male brain theory of autism in half a million people. Proc Natl Acad Sci U S A. 2018;115(48):12152-7. https://doi.org/10.1073/pnas.1811032115.

42. Dawson G, Watling R. Interventions to facilitate auditory, visual, and motor integration in autism: a review of the evidence. J Autism Dev Disord. 2000; 30(5):415-21. https://doi.org/10.1023/a:1005547422749.

43. Goldstein H. Commentary: interventions to facilitate auditory, visual, and motor integration in autism: 'show me the data'. J Autism Dev Disord. 2000; 30(5):423-5. https://doi.org/10.1023/a:1005599406819.

44. Hill EL, Frith U. Understanding autism: insights from mind and brain. Philos Trans R Soc B. 2003;358(1430):281-9. https://doi.org/10.1098/rstb.2002.1209.

45. Minshew NJ, Hobson JA. Sensory sensitivities and performance on sensory perceptual tasks in high-functioning individuals with autism. J Autism Dev Disord. 2008;38(8):1485-98. https://doi.org/10.1007/s10803-007-0528-4.

46. DuBois D, Lymer E, Gibson BE, Desarkar P, Nalder E. Assessing sensory processing dysfunction in adults and adolescents with autism spectrum disorder: a scoping review. Brain Sci. 2017;7(8):108. https://doi.org/10.3390/ brainsci7080108

47. Tomcheck SD, Dunn W. Sensory processing in children with and without autism: a comparative study using the short sensory profile. Am J Occup Ther. 2007;61(2):190-200. https://doi.org/10.5014/ajot.61.2.190.

48. Baron-Cohen S, Jolliffe T, Mortimore C, Robertson M. Another advanced test of theory of mind: evidence from very high functioning adults with autism or Asperger syndrome. J Child Psychol Psychiatry. 1997;38(7):813-22. https://doi.org/10.1111/j.1469-7610.1997.tb01599.x.

49. Vellante M, Baron-Cohen S, Melis M, Marrone M, Petretto DR, Masala C, Preti A. The "reading the mind in the eyes" test: systematic review of psychometric properties and a validation study in Italy. Cognitive Neuropsychiatry. 2013;18(4):326-54. https://doi.org/10.1080/13546805.2012. 721728 .

50. Oakley BFM, Brewer R, Bird G, Catmur C. Theory of mind is not theory of emotion: a cautionary note on the reading the mind in the eyes test. J Abnorm Psychol. 2016;125(6):818-23. https://doi.org/10.1037/abn0000182.

51. Peñuelas-Calvo I, Sareen A, Sevilla-Llewellyn-Jones J, Fernández-Berrocal P. The "reading the mind in the eyes" test in autism-spectrum disorders comparison with healthy controls: a systematic review and meta-analysis. J Autism Dev Disord. 2019;49(3):1048-61. https://doi.org/10.1007/s10803-0183814-4.

52. Witkin H, Oltman I, Rash E, Karp S. A manual for the embedded figures test. Palo Alto: Consulting Psychologists Press; 1971.

53. Baron-Cohen S, Hammer J. Parents of children with Asperger syndrome: what is the cognitive phenotype? J Cogn Neurosci. 1997;9(4):48-554. https://doi.org/10.1162/jocn.1997.9.4.548.

54. Cribb SJ, Olaithe M, Di Lorenzo R, Dunlop PD, Maybery MT. Embedded figures test performance in the broader autism phenotype: a meta-analysis. J Autism Dev Disord. 2016;46(9):2924-39. https://doi.org/10.1007/s10803016-2832-3.

55. Fan J, McCandliss BD, Sommer T, Raz A, Posner MI. Testing the efficiency and independence of attentional networks. J Cogn Neurosci. 2002;14(3): 340-7. https://doi.org/10.1162/089892902317361886.

56. Posner Ml. Orienting of attention. Q J Exp Psychol. 1980;32(1):3-25. https://doi.org/10.1080/00335558008248231.

57. Eriksen BA, Eriksen CW. Effects of noise letters upon the identification of a target letter in a nonsearch task. Percept Psychophys. 1974;16(1):143-9. https://doi.org/10.3758/BF03203267.

58. Allen $\mathrm{G}$, Courchesne E. Attention function and dysfunction in autism. Front Biosci. 2001;6:D105-19.

59. Reinholdt-Dunne ML, Mogg K, Bradley BP. Attention control: relationships between self-report and behavioural measures, and symptoms of anxiety and depression. Cognit Emot. 2013;27(3):430-40. https://doi.org/10.1080/ 02699931.2012.715081.

60. Benton AL, Hamsher KS. Multilingual aphasia examination. New York: Oxford University Press; 1989

61. Lezak MD. Neuropsychological assessment (3/e). New York: Oxford University Press; 1995.

62. Unsworth N, Miller JD, Lakey CE, Young DL, Meeks JT, Campbell WK, Goodie AS. Exploring the relations among executive functions, fluid intelligence, and personality. J Individ Differ. 2009;30(4):194-200. https://doi.org/10.1027/ 1614-0001.30.4.194.

63. Frith $U$, de Vignemont F. Egocentrism, allocentrism, and Asperger syndrome. Conscious Cogn. 2005;14(4):719-38. https://doi.org/10.1016/j. concog.2005.04.006.

64. Wechsler D. Wechsler abbreviated scale of intelligence. New York: The Psychological Corporation; 1999.

65. Golay X, Pruessmann KP, Weiger M, Crelier GR, Folkers PJ, Kollias SS, Boesiger P. PRESTO-SENSE: an ultrafast whole-brain fMRI technique. Magn Reson Med. 2000;43(6):779-86. https://doi.org/10.1002/1522-2594(200006)43: 6<779::aid-mrm1>3.0.co;2-4.

66. Neggers SF, Hermans EJ, Ramsey NF. Enhanced sensitivity with fast threedimensional blood-oxygen-level-dependent functional MRI: comparison of SENSE-PRESTO and 2D-EPI at 3 T. NMR Biomed. 2008;21(7):663-76. https://doi.org/10.1002/nbm.1235.

67. van den Heuvel MP, Stam CJ, Boersma M, Hulshoff Pol HE. Small-world and scale-free organization of voxel-based resting-state functional connectivity in the human brain. Neurolmage. 2008;43(3):528-39. https://doi.org/10.1016/ j.neuroimage.2008.08.010.

68. Chao-Gan Y, Yu-Feng Z. DPARSF: a MATLAB toolbox for "pipeline" data analysis of resting-state fMRI. Front Syst Neurosci. 2010;4:13. https://doi.org/ 10.3389/fnsys.2010.00013.

69. Cordes D, Haughton VM, Arfanakis K, Wendt GJ, Turski PA, Moritz CH, Quigley MA, Meyerand ME. Mapping functionally related regions of brain with functional connectivity MR imaging. Am J Neuroradiol. 2000;21(9): 1636-44.

70. Leemans A, Jones DK. The B-matrix must be rotated when correcting for subject motion in DTI data. Magn Reson Med. 2009;61(6):1336-49. https://doi.org/10.1002/mrm.21890.

71. Behrens TE, Berg HJ, Jbabdi S, Rushworth MF, Woolrich MW. Probabilistic diffusion tractography with multiple fibre orientations: what can we gain? Neurolmage. 2007;34(1):144-55. https://doi.org/10.1016/j.neuroimage.2006. 09.018 .

72. Strogatz SH. Exploring complex networks. Nature. 2001;410:268-76. https://doi.org/10.1038/35065725.

73. Barttfeld P, Wicker B, Cukier S, Navarta S, Lew S, Sigman M. A big-world network in ASD: dynamical connectivity analysis reflects a deficit in longrange connections and an excess of short-range connections. Neuropsychologia. 2011;49(2):254-63. https://doi.org/10.1016/j. neuropsychologia.2010.11.024.

74. Achard S, Bullmore ET. Efficiency and cost of economical brain functional networks. PLoS Comput Biol. 2007;3(2):e17. https://doi.org/10.1371/journal. pcbi.0030017.

75. Onnela J, Saramäki J, Kertész J, Kaski K. Intensity and coherence of motifs in weighted complex networks. Phys Rev E Stat Nonlin Biol Soft Matter Phys. 2005;71:065103. https://doi.org/10.1103/PhysRevE.71.065103.

76. Watts DJ, Strogatz SH. Collective dynamics of 'small-world' networks. Nature. 1998;393:440-2.

77. Latora V, Marchiori M. Efficient behavior of small-world networks. Phys Rev Lett. 2001;87(19):198701. https://doi.org/10.1103/PhysRevLett.87.198701.

78. Power JD, Barnes KA, Snyder AZ, Schlaggar BL, Petersen SE. Spurious but systematic correlations in functional connectivity MRI networks arise from subject motion. Neurolmage. 2012;59(3):2142-54. https://doi.org/10.1016/j. neuroimage.2011.10.018

79. Smith SM, Nichols TE, Vidaurre D, Winkler AM, Behrens TEJ, Glasser MF, Ugurbil K, Barch DM, Van Essen DC, Miller KL. Nat Neurosci. 2015;18:1565-7. https://doi.org/10.1038/nn.4125.

80. Benjamini $Y$, Hochberg $Y$. Controlling the false discovery rate: a practical and powerful approach to multiple testing. J R Stat Soc Ser B. 1995;57(1): 289-300. https://doi.org/10.1111/j.2517-6161.1995.tb02031.x.

81. Brian JA, Bryson SE, Zwaigenbaum L. Autism spectrum disorder in infancy: developmental considerations in treatment targets. Curr Opin Neurol. 2015; 28(2):117-23. https://doi.org/10.1097/WCO.0000000000000182. 
82. Baranek GT, Woynaroski TG, Nowell S, Turner-Brown L, DuBay M, Crais ER, Watson LR. Cascading effects of attention disengagement and sensory seeking on social symptoms in a community sample of infants at-risk for a future diagnosis of autism spectrum disorder. Dev Cogn Neurosci. 2018;29: 30-40. https://doi.org/10.1016/j.den.2017.08.006.

83. Braga RM, Buckner RL. Parallel interdigitated distributed networks within the individual estimated by intrinsic functional connectivity. Neuron. 2017;95(2): 457-71. https://doi.org/10.1016/j.neuron.2017.06.038.

84. Asperger H. Die 'autistischen psychopathen' im kindesalter. Arch Psychiatr Nervenkr. 1944;117(1):76-136.

85. Cantor PA. Gilligan unbound: pop culture in the age of globalization. Lanham: Rowman \& Littlefield; 2001.

86. Rubenstein JLR, Merzenich MM. Model of autism: increased ratio of excitation/inhibition in key neural systems. Genes Brain Behav. 2003;2(5): 255-67. https://doi.org/10.1034/j.1601-183X.2003.00037.x.

87. Shew WL, Yang H, Yu S, Roy R, Plenz D. Information capacity and transmission are maximized in balanced cortical networks with neuronal avalanches. J Neurosci. 2011;31(1):55-63. https://doi.org/10.1523/JNEUROSCl. 4637-10.2011.

88. Belmonte MK, Allen G, Beckel-Mitchener A, Boulanger LM, Carper RA, Webb SJ. Autism and abnormal development of brain connectivity. J Neurosci. 2004;24(42):9228-31. https://doi.org/10.1523/JNEUROSCI.3340-04.2004.

89. Deco G, Ponce-Alvarez A, Hagmann P, Romani GL, Mantini D, Corbetta M. How local excitation-inhibition ratio impacts the whole brain dynamics. J Neurosci. 2014;34(23):7886-98. https://doi.org/10.1523/JNEUROSCI.506813.2014

90. Ray S, Miller M, Karalunas S, Robertson C, Grayson DS, Cary RP, Hawkey E, Painter JG, Kriz D, Fombonne E, Nigg JT, Fair DA. Structural and functional connectivity of the human brain in autism spectrum disorders and attention-deficit/hyperactivity disorder: a rich club-organization study. Hum Brain Mapp. 2014;35(12):6032-48. https://doi.org/10.1002/hbm.22603.

91. Belmonte MK, Gomot M, Baron-Cohen S. Visual attention in autism families: 'unaffected' sibs share atypical frontal activation. J Child Psychol Psychiatry. 2010;51(3):259-76. https://doi.org/10.1111/j.1469-7610.2009.02153.x.

92. Belmonte MK. Obligatory processing of task-irrelevant stimuli: a hallmark of autistic cognitive style within and beyond the diagnosis. Biolog Psychiatry Cogn Neurosci Neuroimaging. 2017;2(6):461-3. https://doi.org/10.1016/j. bpsc.2017.07.002.

93. Belmonte MK, Yurgelun-Todd DA. Functional anatomy of impaired selective attention and compensatory processing in autism. Cogn Brain Res. 2003b; 17(3):651-64. https://doi.org/10.1016/S0926-6410(03)00189-7.

94. Murias M, Webb SJ, Dawson G. Resting state cortical connectivity reflected in EEG coherence in individuals with autism. Biol Psychiatry. 2007;62(3):2703. https://doi.org/10.1016/j.biopsych.2006.11.012.

95. Coben R, Clarke AR, Hudspeth W, Barry RJ. EEG power and coherence in autistic spectrum disorder. Clin Neurophysiol. 2008;119(5):1002-9. https://doi.org/10.1016/j.clinph.2008.01.013.

96. Kitzbichler MG, Khan S, Ganesan S, Vangel MG, Herbert MR, Hämäläinen MS, Kenet T. Altered development and multifaceted band-specific abnormalities of resting state networks in autism. Biol Psychiatry. 2015;77(9):794-804. https://doi.org/10.1016/j.biopsych.2014.05.012.

97. Khan S, Michmizos K, Tommerdahl M, Ganesan S, Kitzbichler MG, Zetino M, Garel KA, Herbert MR, Hämäläinen MS, Kenet T. Somatosensory cortex functional connectivity abnormalities in autism show opposite trends, depending on direction and spatial scale. Brain. 2015;138(5):1394-409. https://doi.org/10.1093/brain/awv043.

98. Scheeringa R, Fries P, Petersson K, Oostenveld R, Grothe I, Norris DG, Hagoort $P$, Bastiaansen MCM. Neuronal dynamics underlying high- and low-frequency EEG oscillations contribute independently to the human BOLD signal. Neuron. 2011;69(3):572-83. https:/doi.org/10.1016/j.neuron.2010.11.044.

99. Lachaux J, Fonlupt P, Kahane P, Minotti L, Hoffmann D, Bertrand O, Baciu M. Relationship between task-related gamma oscillations and BOLD signal: New insights from combined fMRI and intracranial EEG. Hum Brain Mapp. 2007;28(12):1368-75. https://doi.org/10.1002/hbm.20352.

100. Happé F, Ronald A. The 'fractionable autism triad': a review of evidence from behavioural, genetic, cognitive and neural research. Neuropsychol Rev. 2008;18(4):287-304. https://doi.org/10.1007/s11065-008-9076-8.

101. Mandy WPL, Skuse DH. Research review: what is the association between the social-communication element of autism and repetitive interests, behaviours and activities? J Child Psychol Psychiatry. 2008:49(8):795-808. https://doi.org/10.1111/j.1469-7610.2008.01911.x.
102. Palmer CJ, Paton B, Enticott PG, Hohwy J. 'Subtypes' in the presentation of autistic traits in the general adult population. J Autism Dev Disord. 2015; 45(5):1291-301. https://doi.org/10.1007/s10803-014-2289-1.

103. Lewis JD, Evans AC, Pruett JR Jr, Botteron KN, McKinstry RC, Zwaigenbaum L, Estes AM, Collins DL, Kostopoulos P, Gerig G, Dager SR, Paterson S, Schultz RT, Styner MA, Hazlett HC, Piven J. The emergence of network inefficiencies in infants with autism spectrum disorder. Biol Psychiatry. 2017; 82(3):152-4. https://doi.org/10.1016/j.biopsych.2017.03.006.

104. Neufeld J, Kuja-Halkola R, Mevel K, Cauvet É, Fransson P, Bölte S. Alterations in resting state connectivity along the autism trait continuum: a twin study. Mol Autism. 2018;23(7):1659-65. https://doi.org/10.1038/mp.2017.160.

105. Keehn RJJ, Nair S, Pueschel EB, Linke AC, Fishman I, Müller R-A. Atypical local and distal patterns of occipito-frontal functional connectivity are related to symptom severity in autism. Cereb Cortex. 2019;29(8):3319-30. https://doi.org/10.1093/cercor/bhy201.

106. Murray RJ, Debbané M, Fox PT, Bzdok D, Eickhoff SB. Functional connectivity mapping of regions associated with self- and other-processing. Hum Brain Mapp. 2015;36(4):1304-24. https://doi.org/10.1002/hbm.22703.

107. Scholz J, Triantafyllou C, Whitfield-Gabrieli S, Brown EN, Saxe R. Distinct regions of right temporo-parietal junction are selective for theory of mind and exogenous attention. PLoS One. 2009;4(3):e4869. https://doi.org/10. 1371/journal.pone.0004869.

108. Uzefovsky F, Bethlehem RAl, Shamay-Tsoory S, Ruigrok A, Holt R, Spencer M, Chura L, Warrier V, Chakrabarti B, Bullmore E, Suckling J, Floris D, BaronCohen $\mathrm{S}$. The oxytocin receptor gene predicts brain activity during an emotion recognition task in autism. Mol Autism. 2019;10:12. https://doi.org/ 10.1186/s13229-019-0258-4.

109. Bar M, Aminoff EM, Schacter DL. Scenes unseen: the parahippocampal cortex intrisically subserves contextual associations, not scenes or places per se. J Neurosci. 2008;28(34):8539-44. https://doi.org/10.1523/JNEUROSCI.098708.2008.

110. Aminoff EM, Kveraga K, Bar M. The role of the parahippocampal cortex in cognition. Trends Cogn Sci. 2013;17(8):379-90. https://doi.org/10.1016/j.tics. 2013.06.009

111. Buzsáki G, Tingley D. Space and time: the hippocampus as a sequence generator. Trends Cogn Sci. 2018;22(10):853-69. https://doi.org/10.1016/j.tics 2018.07.006.

112. Horwitz B. The elusive concept of brain connectivity. Neurolmage. 2003; 19(2):466-70. https://doi.org/10.1016/S1053-8119(03)00112-5

113. Belmonte MK, Yurgelun-Todd DA. Anatomic dissociation of selective and suppressive processes in visual attention. Neurolmage. 2003a;19(1):180-9. https://doi.org/10.1016/s1053-8119(03)00033-8.

114. Baek K, Morris LS, Kundu P, Voon V. Disrupted resting-state brain network properties in obesity: decreased global and putaminal cortico-striatal network efficiency. Psychol Med. 2017;47(4):585-96. https://doi.org/10.1017/ S0033291716002646.

115. Hu R, Qiu D, Guo Y, Zhao Y, Leatherday C, Wu J, Allen JW. Variability of resting-state functional MRI graph theory metrics across $3 T$ platforms. J Neuroimaging. 2019;29(3):344-7. https://doi.org/10.1111/jon.12603.

116. Beim Graben P, Jimenez-Marin A, Diez I, Cortes JM, Desroches M, Rodrigues S. Metastable resting state brain dynamics. Front Comput Neurosci. 2019;13: 62. https://doi.org/10.3389/fncom.2019.00062.

117. Tavassoli T, Brandes-Aitken A, Chu R, Porter L, Schoen S, Miller LJ, Gerdes MR, Owen J, Mukherjee P, Marco EJ. Sensory over-responsivity: parent report, direct assessment measures, and neural architecture. Mol Autism. 2019;10:4. https://doi.org/10.1186/s13229-019-0255-7.

118. Hasson U, Avidan G, Gelbard H, Vallines I, Harel M, Minshew N, Behrmann M. Shared and idiosyncratic cortical activation patterns in autism revealed under continuous real-life viewing conditions. Autism Res. 2009;2(4):220-31. https://doi.org/10.1002/aur.89.

119. Falahpour M, Thompson WK, Abbott AE, Jahedi A, Mulvey ME, Datko M, Liu T, Müller RA. Underconnected, but not broken? Dynamic functional connectivity MRI shows underconnectivity in autism is linked to increased intra-individual variability across time. Brain Connect. 2016;6(5):403-14. https://doi.org/10.1089/brain.2015.0389.

\section{Publisher's Note}

Springer Nature remains neutral with regard to jurisdictional claims in published maps and institutional affiliations. 